\title{
From Deviations to Shortfalls: The Effects of the FOMC's New Employment Objective
}

\author{
Brent Bundick \\ Federal Reserve Bank of Kansas City \\ Nicolas Petrosky-Nadeau \\ Federal Reserve Bank of San Francisco
}

July 2021

Working Paper 2021-18

https://www.frbsf.org/economic-research/publications/working-papers/2021/18/

\section{Suggested citation:}

Bundick, Brent, Nicolas Petrosky-Nadeau. 2021 "From Deviations to Shortfalls: The Effects of the FOMC's New Employment Objective," Federal Reserve Bank of San

Francisco Working Paper 2021-18. https://doi.org/10.24148/wp2021-18

The views in this paper are solely the responsibility of the authors and should not be interpreted as reflecting the views of the Federal Reserve Bank of San Francisco or the Board of Governors of the Federal Reserve System. 


\title{
From Deviations to Shortfalls: The Effects of the FOMC's New Employment Objective*
}

\author{
Brent Bundick ${ }^{\dagger} \quad$ Nicolas Petrosky-Nadeau ${ }^{\ddagger}$
}

July 2021

\begin{abstract}
The Federal Open Market Committee (FOMC) recently revised its interpretation of its maximum employment mandate. In this paper, we analyze the possible effects of this policy change using a theoretical model with frictional labor markets and nominal rigidities. A monetary policy which stabilizes "shortfalls" rather than "deviations" of employment from its maximum level leads to higher inflation and more hiring at all times due to expectations of more accommodative future policy. Thus, offsetting only shortfalls of employment results in higher nominal policy rates on average which provide more policy space and better outcomes during a zero lower bound episode. Our model suggests that the FOMC's reinterpretation of its employment mandate could alter the business-cycle and longer-run properties of the economy and result in a steeper reduced-form Phillips curve.
\end{abstract}

JEL Classification: E32, E52, J64

Keywords: Monetary Policy, Equilibrium Unemployment, Nominal Rigidities, Zero Lower Bound

${ }^{*}$ We thank A. Lee Smith for helpful discussions. We also appreciate the comments from workshop participants at the Federal Reserve Banks of Kansas City and San Francisco. We thank Shelby Buckman and Logan Hotz for excellent research assistance. The views expressed herein are solely those of the authors and do not necessarily reflect the views of the Federal Reserve Banks of Kansas City or San Francisco, or the Federal Reserve System.

${ }^{\dagger}$ Federal Reserve Bank of Kansas City. Email: brent.bundick@kc.frb.org

${ }^{\ddagger}$ Federal Reserve Bank of San Francisco. Email: nicolas.petrosky-nadeau@sf.frb.org 


\section{Introduction}

At the conclusion of the Federal Reserve's recent policy review, the Federal Open Market Committee (FOMC) made several changes to its Statement on Longer-Run Goals and Strategy. One important change was the Committee's reinterpretation of its maximum employment mandate. Specifically, the Statement now communicates that, "the Committee seeks over time to mitigate shortfalls of employment from the Committee's assessment of its maximum level ..." In contrast, the previous consensus statement cited a desire to stabilize "deviations" of employment from its maximum level. In explaining this policy change, Federal Reserve Chair Jerome Powell stated that, this change "means that we will not tighten monetary policy solely in response to a strong labor market." 1

This policy change from offsetting both positive and negative employment deviations to instead stabilizing one-sided shortfalls introduces an asymmetry in the monetary policy reaction function. In this paper, we analyze the possible effects of this new policy using a theoretical model which combines frictional labor markets, nominal rigidities, and the zero lower bound. To properly account for the asymmetric policy reaction function, we solve our model using a global solution method. In addition, we discipline our model's calibration using observed fluctuations in unemployment, inflation, hours worked, and nominal interest rates over the 25 years immediately preceding the new consensus statement.

A monetary policy which stabilizes "shortfalls" rather than "deviations" of employment from its maximum level affects firm price setting and hiring behavior in all states of the world. Since policymakers will not lean against a tight labor market under a shortfallsstabilization rule, the expectation of more accommodative policy leads forward-looking price setters to set higher prices to maintain their desired markups in the face of higher expected future demand. Similarly, expectations for greater demand for their products cause firms to increase their demand for labor and hiring. This expansionary expectations effect of the shortfalls rule is strongest when the economy is in an expansion and unemployment is below its longer-run value. In contrast, the differences between the hiring and price setting decisions under both policies are smaller when unemployment is high since the expectations of more accommodative policy under a shortfalls policy is sufficiently far off in the future.

The greater price increases and increased hiring under the shortfalls-stabilization rule

\footnotetext{
${ }^{1}$ See Powell (2021). The FOMC revised its Statement on Longer-Run Goals and Monetary Policy Strategy in August 2020 and is available at www.federalreserve.gov/monetarypolicy/files/FOMC_LongerRunGoals.pdf.
} 
leads to higher inflation, employment, and nominal policy rates on average. Switching to a shortfalls rule raises average inflation by about 50 basis points and lowers the longer-run unemployment rate by 20 basis points in our calibrated model. The shift in average inflation more than offsets the downward bias in average inflation stemming from the presence of the zero lower bound and adverse fluctuations in the labor market. Finally, the higher inflation and lower unemployment combine to increase the average nominal policy rate in the economy by roughly 50 basis points. Thus, adopting a shortfalls-stabilization rule provides additional policy space to a central bank facing a zero lower bound (ZLB) constraint.

In addition to these changes in average outcomes for the economy, changing to a one-sided shortfalls rule increases the likelihood of robust expansions with higher inflation and lower unemployment. Specifically, our model predicts a pronounced decline in the probability of inflation outcomes below $1 \%$ while the realizations of inflation above $3 \%$ become more likely. With respect to the labor market, our model implies that low unemployment outcomes $(4 \%$ or below) become more frequent under the shortfalls rule while we see little change in the frequency of high unemployment rates above $7 \%$. Thus, a shortfalls rule does not prevent high unemployment rates during recessions but instead ensures a more rapid return to full employment in a recovery and more sustained periods of low unemployment during expansions. Taken together, our model implies a steepening of the reduced-form Phillips curve if policymakers change to a shortfalls-stabilization rule.

These changes in the business-cycle and longer-run properties of the economy under a shortfalls-stabilization rule also lead to better outcomes at the zero lower bound relative to a symmetric deviations rule. A shortfalls-only policy rule helps stabilize the economy at the zero lower bound since households and firms understand that the central bank will deliver a more accommodative policy in the future. This helps offset the contractionary effects of the zero lower bound today. Specifically, a one-sided shortfalls rule performs better than a deviations-stabilization rule as it does not try and offset positive employment developments during the recovery. Moreover, the zero lower bound binds less often and results in shorter zero lower bound episodes under a shortfalls-stabilization rule since higher average inflation and employment lead to higher nominal interest rates on average.

Our work complements other recent research on the FOMC's adoption of a flexible average inflation targeting framework, another key change adopted in its most recent Statement on Longer-Run Goals and Strategies. ${ }^{2}$ In addition to changing its interpretation of its em-

\footnotetext{
${ }^{2}$ See Altig et al. (2020) for an overview of the research undertaken as part of the Federal Reserve's 2019 review of its monetary policy framework.
} 
ployment mandate, the FOMC stated that its intention for inflation to average two percent over time. Thus, if inflation has run persistently below two percent, the Committee will pursue inflation modestly above two percent for some time going forward. Mertens and Williams (2019), Amano et al. (2020), and Nessen and Vestin (2005) show that average inflation targeting can help alleviate the downward pressure on longer-term inflation expectations caused by the zero lower bound. Our model shows that a policy rule which only offsets employment shortfalls also raises longer-term inflation, suggesting that the reinterpretation of the employment mandate complements and reinforces the likely desired policy outcomes of the FOMC's flexible average inflation targeting framework.

Our model shares features with a large literature which studies the interactions between search and matching frictions in the labor market and nominal pricing rigidities such as Walsh (2005), Krause and Lubik (2007), Gertler, Sala and Trigari (2008), Christiano, Eichenbaum and Trabandt (2016), and many others. In particular, Krause and Lubik (2007), emphasize that the measure of marginal cost relevant for inflation includes the present-value of a new hire in a frictional labor market, a feature at the center of some of our main results. However, our model also incorporates the zero lower bound and demand shocks, two features which are often absent from models in the literature. We examine outcomes at the zero lower bound since the FOMC cited it as an important rationale behind the recent changes to its framework. In addition, the inclusion of demand shocks in our model help reproduce the downward-sloping Phillips curve between inflation and unemployment we observe in the data and generate reasonable zero lower bound episodes. Thus, our model is closest to both Albertini and Poirier (2015) which examine an extension of unemployment benefits at the zero lower bound in a model with frictional labor markets, nominal rigidities, and demand shocks.

Our work also contributes to the large literature on the conduct of monetary policy in the presence of search frictional labor markets beginning with Cooley and Quadrini (1999), Walsh (2005), and many others. In this context, our work relates to Sala, Soderstrom and Trigari (2008) and Faia (2008) which compares the performance of central bank policy rules targeting different measures of output or unemployment. Another strand of this work, such as Blanchard and Galí (2010), focuses on the role of real-wage rigidity for the conduct of optimal monetary policy. To keep our model as simple as possible, our baseline model features bilateral Nash bargaining between workers and firms over hours worked and wages, instead of either staggered wage bargaining as in Gertler and Trigari (2009) or alternative offers bargaining as in Hall and Milgrom (2008) or Christiano, Eichenbaum and Trabandt (2016). 
Lastly, our work relates to the literature on optimal monetary policy in the face of nonlinearities in economy. Orphanides and Wieland (2000) and Dolado, Maria-Dolores and Naveira (2005) derive the implications of a nonlinear Phillips curve for optimal monetary policy rules within a conventional symmetric quadratic loss function framework. They argue that the policy reaction function should include an asymmetry with a stronger reaction to inflation or employment when they are above their respective targets. In contrast, Surico (2007) and Gust, López-Salido and Meyer (2017) show that asymmetric loss functions naturally lead to asymmetries in the central bank's reaction function which result in a positive inflation bias when policymakers have greater aversion to contractions than expansions. Relative to this work, the changes in the economy's reduced-form Phillips curve we highlight arise endogenously if policymakers adopt a shortfalls-stabilization rule. In addition, our shortfallsstabilization rule shares features with the endogenous regime switching policy rules originally examined by Davig and Leeper (2006). Finally, Coibion, Gorodnichenko and Wieland (2012) show that, when policymakers face a zero lower bound constraint, raising the inflation target may be too blunt an instrument to effectively reduce the severity of zero lower bound episodes. While we do not explicitly consider optimal policy in this paper, our results suggest that adopting a shortfalls rule may provide an alternative solution for improving outcomes at the zero lower bound.

The rest of the paper is organized as follows: Section 2 describes the model environment, specifies the monetary policy reaction functions under both deviations- or shortfallsstabilization rules, and provides details on the calibration of the model to the US economy. Section 3 describes the main results of the paper and gives the intuition for the impact of the shortfalls stabilization-rule on the economy.

\section{A Model of Labor Markets \& Nominal Rigidities}

To examine the possible effects of the FOMC's new interpretation of its employment mandate, we posit, calibrate, and solve a theoretical model of the U.S. economy. The key features of our economic environment are frictional labor markets, nominal rigidities in price setting, and a zero lower bound constraint on short-term nominal interest rates. To capture the asymmetry in the FOMC's new employment objective, we allow for the central bank's policy reaction function to change as a function of the current state of the economy. Fluctuations in the economy are driven by changes in household demand and productivity. To account for the potentially asymmetric policy reaction function, we solve our model using a global solution method and discipline our model's calibration using observed fluctuations in 
economy over the 25 years immediately preceding the new interpretation of its employment mandate. Since our primary focus is determining the possible effects from the change in the policy reaction function, we first describe our specifications for monetary policy before providing details on the other features of the model.

\subsection{Monetary Policy}

In our model, monetary policy sets the short-term nominal interest rate to systematically offset adverse fluctuations in inflation and unemployment. To examine the possible effects from the change in the FOMC's employment objective, we posit two different rules for the central bank's reaction function. The first rule intends to capture the setting of the nominal policy rate prior to the announcement of the new consensus statement in August 2020. We refer to the first specification as the Deviations rule as it treats deviations of inflation and unemployment from their respective targets symmetrically:

$$
r_{t}^{d}=r+\phi_{\pi}\left(\pi_{t}-\pi^{*}\right)+\phi_{u}\left(U_{t}-U^{*}\right)
$$

where $r_{t}^{d}$ is the central bank's desired policy rate, $\pi_{t}=\log \left(P_{t} / P_{t-1}\right)$ denotes inflation, $P_{t}$ denotes the price level, and $U_{t}$ denotes the unemployment rate. The parameters $\phi_{\pi}>0$ and $\phi_{u}<0$ determine the policy reactions to deviations of inflation from the central bank's inflation target $\pi^{*}$ and fluctuations of unemployment from its longer-run natural rate $U^{*}{ }^{3}$

In the second rule, monetary policy no longer reacts to a labor market when unemployment falls below its longer-run level. We denote this second specification as the Shortfalls rule as it aims to capture the reinterpretation of the employment mandate in the recent Goals and Strategies statement.

$$
r_{t}^{d}= \begin{cases}r+\phi_{\pi}\left(\pi_{t}-\pi^{*}\right)+\phi_{u}\left(U_{t}-U^{*}\right) & \text { if } U_{t} \geq U^{*} \\ r+\phi_{\pi}\left(\pi_{t}-\pi^{*}\right) & \text { if } U_{t}<U^{*}\end{cases}
$$

This policy is consistent with Powell (2021)'s discussion of the new employment objective as policymakers in the model will not adjust the stance of policy solely to a tight labor market. Under both the deviations and shortfalls rules, however, monetary policy faces a zero lower

\footnotetext{
${ }^{3}$ Equivalently the policy rule may be expressed in terms of setting the gross nominal rate and the reaction function in proportional departures from target. See Section B.2 of the Appendix for a more detailed discussion and mapping between the two representations.
} 
bound constraint such that actual nominal policy rates $r_{t}$ cannot fall below zero:

$$
r_{t}=\max \left(0, r_{t}^{d}\right)
$$

In this paper, we examine the possible macroeconomic effects if the central bank chooses to follow the one-sided employment shortfalls rule versus the symmetric deviations rule.

\subsection{Households}

Our model features a representative household in which a fraction $N_{t}$ of the unit mass of members are employed, work $H_{t}$ hours on the job at an hourly wage $W_{t}$, and a fraction $U_{t}$ are unemployed and searching for work. The representative household chooses consumption $C_{t}$ and holdings of the one-period nominal bond $B_{t}$ to maximize its lifetime utility $J_{t}$ :

$$
\begin{array}{r}
J_{t}=\max _{C_{t}, B_{t}}\left\{\exp \left(\gamma_{t}\right) \frac{C_{t}^{1-\sigma}}{1-\sigma}+\nu_{0} \frac{\left(1-H_{t}\right)^{1-\nu_{1}}}{1-\nu_{1}} N_{t}+\nu_{u} U_{t}+\beta E_{t}\left[J_{t+1}\right]\right\} \\
\text { subject to } C_{t}+T_{t}+\frac{B_{t}}{P_{t} R_{t}}=\frac{B_{t-1}}{P_{t}}+W_{t} H_{t} N_{t}+b U_{t}+D_{t}
\end{array}
$$

where $\beta$ represents household discount factor over time. The parameters $\sigma>0, \nu_{0}>0$ and $\nu_{1}>0$ affect the utility of consumption and the disutility of hours worked out of a total amount of time available (which is normalized to 1 each period). $\nu_{u}$ affects the utility of non-employment and $b$ denotes unemployment benefits. Finally, $R_{t}=\exp \left(r_{t}\right)$ denotes the gross nominal interest rate, $T_{t}$ denotes lump sum taxes to fund unemployment benefits, and $D_{t}$ denotes dividends from owning all shares in wholesale and retail firms. This specification of preferences over consumption, hours worked on the job, and employment is close the foundational work of the Andolfatto (1996) incorporating labor market search frictions into real business cycles. ${ }^{4}$

\footnotetext{
${ }^{4}$ Since Andolfatto (1996), a majority of the work studying the business cycle in models of equilibrium unemployment do not consider the intensive margin of hours adjustments and assumes risk neutral workers. These two elements have been found not to be central for the dynamics of the main outcomes of interest in that stream of research, namely the rate of unemployment and job vacancies, unless they enter and affect the dynamics of equilibrium wages (see Rudanko (2009) for an example of wage rigidity arising from employers offering wage contracts to risk averse workers). Among New Keynesian environments with frictional labor markets, in Krause and Lubik (2007), Walsh (2005), Gertler, Sala and Trigari (2008), and Christiano, Eichenbaum and Trabandt (2016) hours worked or employment do not enter the period utility function. The first assume CRRA preferences and the latter three works assume log-preferences with habit formation in consumption. Blanchard and Galí (2010), who study optimal monetary policy in a model with a search frictional unemployment, assume concave disutility to employment. Moscarini and Postel-Vinay (2017) assume households have concave preferences over consumption and linear preferences over leisure, where household members are either employed or unemployed.
} 
The variable $\gamma_{t}$ is an exogenous random process that shifts the level of utility over consumption and changes in $\gamma_{t}$ generate fluctuations in household demand over time through the household's stochastic discount factor. The law of motion for this preference shock process is as follows:

$$
\gamma_{t}=\rho_{\gamma} \gamma_{t-1}+\sigma_{\gamma} \varepsilon_{t}^{\gamma}
$$

where $\rho_{\gamma} \in(0,1)$ and $\sigma_{\gamma}>0$ control the persistence and volatility of the demand shocks, and $\varepsilon_{t}^{\gamma}$ is an independently and identically-distributed standard normal shock.

Denote $\lambda_{t}^{C}$ as the Lagrange multiplier on the household's budget constraint and denote $\Pi_{t}=P_{t} / P_{t-1}$ as the gross inflation rate. The household's first-order condition for bond holdings yields the Euler equation

$$
1=E_{t}\left\{M_{t, t+1} \frac{R_{t}}{\Pi_{t+1}}\right\}
$$

in which the stochastic discount factor, $M_{t, t+1}$, is given by:

$$
M_{t, t+1} \equiv \beta\left(\frac{\lambda_{t+1}^{C}}{\lambda_{t}^{C}}\right)=\beta\left(\frac{\exp \left(\gamma_{t+1}\right)}{\exp \left(\gamma_{t}\right)}\right)\left(\frac{C_{t+1}}{C_{t}}\right)^{-\sigma}
$$

\subsection{The Labor Market}

Firms post a number of job vacancies, $V_{t}$, to attract jobs seekers and employed workers are subject to a job separation shock at rate $s$ at the end of a period. Each vacant position costs $\kappa_{t}=\kappa_{0}+\kappa_{1} q_{t}>0$ units of final output per unit of time. $\kappa_{0}>0$ is a variable cost and $\kappa_{1}$ a fixed post hiring cost paid by a representative firm after hiring. $q_{t}$ is the vacancy filling rate discussed below. Vacancies are filled via a constant returns to scale matching function, $G\left(U_{t}, V_{t}\right)$. We define labor market tightness as $\theta_{t} \equiv V_{t} / U_{t}$. The probability for a worker searching in the labor market to find a job per unit of time (the job finding rate), denoted $f\left(\theta_{t}\right)$, is:

$$
\frac{G\left(U_{t}, V_{t}\right)}{U_{t}}=f\left(\theta_{t}\right) \text { with } f^{\prime}\left(\theta_{t}\right)>0
$$

The probability for a vacancy to be filled per unit of time (the vacancy filling rate) is:

$$
\frac{G\left(U_{t}, V_{t}\right)}{V_{t}}=q\left(\theta_{t}\right) \text { with } q^{\prime}\left(\theta_{t}\right)<0
$$

and such that $q\left(\theta_{t}\right) V_{t}$ is the number of new hires. Employment, $N_{t}$, evolves as

$$
N_{t+1}=(1-s) N_{t}+q\left(\theta_{t}\right) V_{t}
$$


The matching function is specified as $G\left(U_{t}, V_{t}\right)=\frac{U_{t} V_{t}}{\left(U_{t}^{\iota}+V_{t}^{\iota}\right)^{1 / \iota}}$, in which $\iota>0$ is a constant parameter. This matching function, specified as in Haan, Ramey and Watson (2000), has the desirable property that matching probabilities fall between zero and one. The job finding and filling rates are given by $f\left(\theta_{t}\right)=\left(1+\theta_{t}^{-\iota}\right)^{-1 / \iota}$ and $q\left(\theta_{t}\right)=\left(1+\theta_{t}^{\iota}\right)^{-1 / \iota}$, respectively.

\subsection{Aggregating sector}

The aggregation sector produces the aggregate final consumption good $Y_{t}$ using a basket of differentiated retail goods as inputs. Denote by $Y_{t}(j)$ a type $j \operatorname{retail} \operatorname{good}$ for $j \in[0,1]$. We assume that

$$
Y_{t}=\left(\int_{0}^{1} Y_{t}(j)^{\frac{\omega-1}{\omega}} \mathrm{d} j\right)^{\frac{\omega}{\omega-1}}
$$

where $\omega>1$ denotes the elasticity of substitution between differentiated products. Expenditure minimization implies a demand for type $j$ retail good that is inversely related to the relative price, with the demand schedule given by

$$
Y_{t}^{d}(j)=\left(\frac{P_{t}(j)}{P_{t}}\right)^{-\omega} Y_{t}
$$

where $Y_{t}^{d}(j)$ and $P_{t}(j)$ denote the demand for and the price of retail good of type $j$, respectively. The price index $P_{t}$ is related to individual prices $P_{t}(j)$ through

$$
P_{t}=\left(\int_{0}^{1} P_{t}(j)^{\frac{1}{1-\omega}} \mathrm{d} j\right)^{1-\omega} .
$$

\subsection{Retail sector}

There is a continuum of retail goods producers each producing a differentiated product using a homogenous intermediate good produced by a wholesale sector as input. The production function of a retail good of type $j \in[0,1]$ is given by

$$
Y_{t}(j)=I_{t}(j)
$$

where $I_{t}(j)$ is the input of intermediate goods used by retailer $j$, purchased at the unit price $\psi_{t}$ on a competitive intermediate goods market.

Retail goods producers are price takers in the input market and monopolistic competitors in the product markets, where they set the price for their goods taking as given by the demand 
schedule in equation (12) and in the price index in equation (13). We assume quadratic costs to adjusting prices:

$$
\frac{\Omega}{2}\left(\frac{P_{t}(j)}{\Pi P_{t-1}}-1\right)^{2} Y_{t}
$$

where the parameter $\Omega>0$ measures the cost of price adjustments and $\Pi$ denotes the deterministic steady state inflation rate. Price adjustment costs are assumed to be in units of aggregate output.

A retail firm that produces good $j$ maximizes the value of its equity $S_{t}^{r}$ by choosing the price $P_{t}(j)$ for its differentiated good, solving the problem:

$$
S_{t}^{r} \equiv \max _{P_{t}(j)} E_{t}\left[\sum_{i=0}^{\infty} M_{t, t+i}\left[\left(\frac{P_{t+i}(j)}{P_{t+i}}-\psi_{t+i}\right) Y_{t+1}^{d}(j)-\frac{\Omega}{2}\left(\frac{P_{t+i}(j)}{\Pi P_{t+i-1}}-1\right)^{2} Y_{t+i}\right]\right]
$$

The optimal price setting decision implies that, in a symmetric equilibrium with $P_{t}(j)=$ $P_{t}$ for all $j$, the input price $\psi_{t}$ and price inflation $\Pi_{t}$ are related through the equilibrium condition:

$$
\frac{\Pi_{t}}{\Pi}\left(\frac{\Pi_{t}}{\Pi}-1\right)=\frac{\omega}{\Omega}\left(\psi_{t}-\frac{\omega-1}{\omega}\right)+E_{t} M_{t, t+1} \frac{Y_{t+1}}{Y_{t}} \frac{\Pi_{t+1}}{\Pi}\left(\frac{\Pi_{t+1}}{\Pi}-1\right)
$$

in which currently inflation is increasing in the input price $\psi_{t}$, and in expected future demand $\left(Y_{t+1}\right)$ and inflation $\left(\Pi_{t+1}\right)$.

\subsection{Wholesale sector}

Firms in the wholesale sector produce with labor hired on from a labor market subject to search frictions. Output, sold at unit price $\psi_{t}$, is produced with a production technology $X_{t} N_{t} H_{t}^{\alpha}$, where $H_{t}$ are hours of work on the job per worker, $\alpha \in(0,1)$, and $X_{t}$ is aggregate productivity in the wholesale sector. The latter follows the law of motion for $x_{t} \equiv \log \left(X_{t}\right)$ :

$$
x_{t}=\rho_{x} x_{t-1}+\sigma_{x} \varepsilon_{t}^{x},
$$

in which $\rho_{x} \in(0,1)$ is the persistence, $\sigma_{x}>0$ is the conditional volatility, and $\varepsilon_{t}^{x}$ is an independently and identically-distributed standard normal shock.

The wage rate $W_{t}$ and hours of work $H_{t}$ are determined through bargaining with workers, as discussed below. The firm posts an optimal number of job vacancies to maximize the cum- 
dividend market value of equity, denoted $S_{t}^{w}$, taking the vacancy filling rate, employment, wage and hours of work as given:

$$
S_{t}^{w} \equiv \max _{\left\{V_{t+i}, N_{t+i+1}\right\}_{i=0}^{\infty}} E_{t}\left[\sum_{i=0}^{\infty} M_{t, t+i}\left[\psi_{t+i} X_{t+i} N_{t+1} H_{t+i}^{\alpha}-W_{t+i} H_{t+i} N_{t+i}-\kappa_{t+i} V_{t+i}\right]\right]
$$

subject to the employment accumulation equation (10) and a nonnegativity constraint on vacancies as the only source of job destruction in the model is the exogenous separation of employed workers from the firm:

$$
V_{t} \geq 0
$$

Let $\lambda_{t}^{V}$ denote the multiplier on the non-negativity constraint rewritten as $q\left(\theta_{t}\right) V_{t} \geq 0$. From the first-order conditions with respect to $V_{t}$ and $N_{t+1}$, we obtain the intertemporal job creation condition:

$$
\frac{\kappa_{t}}{q\left(\theta_{t}\right)}-\lambda_{t}^{V}=E_{t}\left[M_{t, t+1}\left[\psi_{t+1} X_{t+1} H_{t+1}^{\alpha}-W_{t+1} H_{t+1}+(1-s)\left[\frac{\kappa_{t+1}}{q\left(\theta_{t+1}\right)}-\lambda_{t+1}^{V}\right]\right]\right]
$$

Intuitively, the marginal cost of hiring at time $t$ equals the marginal value of employment to the firm, which in turn equals the marginal benefit of hiring at period $t+1$, discounted to $t$. The marginal benefit at $t+1$ includes the marginal revenue from an employed worker, $\psi_{t+1} X_{t+1} H_{t+1}^{\alpha}$, net of the wage bill, $W_{t+1} H_{t+1}$, plus the marginal value of a retained worker into the next period, which is equal the marginal cost of hiring at $t+1$. Finally, the optimal vacancy policy also satisfies the Kuhn-Tucker conditions:

$$
q_{t} V_{t} \geq 0, \quad \lambda_{t}^{V} \geq 0, \quad \text { and } \quad \lambda_{t}^{V} q_{t} V_{t}=0
$$

\subsection{Wages and Hours of Work}

A common approach, which we follow here, is to assume workers and firms engage in bilateral Nash bargaining over hours and wages. Assuming this takes place at the beginning of each period, after observing the state of the economy, hours and wages are the solution to

$$
\Lambda_{t}=\max _{W_{t}, H_{t}}\left(\frac{J_{N t}-J_{U t}}{\lambda_{t}^{C}}\right)^{\eta}\left(S_{N, t}^{w}-S_{V, t}^{w}\right)^{1-\eta}
$$

where $\eta \in(0,1)$ is the workers' relative bargaining weight, and $\left(J_{N t}-J_{U t}\right)$ and $\left(S_{N, t}^{w}-S_{V, t}^{w}\right)$ are the worker's and the firm's respective labor match surpluses (defined in appendix B, 
along with detailed derivations). This leads to an equilibrium condition for hours:

$$
\frac{\nu_{0}}{\lambda_{t}^{C}}\left(1-H_{t}\right)^{-\nu_{1}}=\alpha \psi_{t} X_{t} H_{t}^{\alpha-1}
$$

equating the marginal utility of hours of leisure to the marginal revenue product of an additional hour of work .

The resulting Nash bargained wage is most easily expressed as compensation per worker $W_{t} H_{t}$ :

$$
W_{t} H_{t}=\eta\left[\psi_{t} X_{t} H_{t}^{\alpha}+\kappa_{t} \theta_{t}\right]+(1-\eta) Z_{t},
$$

which is increasing in the marginal revenue product of labor, conditions in the labor market through changes in labor market tightness $\theta_{t}$, and in the variable $Z_{t}=b+\nu_{u} / \lambda_{t}^{C}-$

$\nu_{0} \frac{\left(1-H_{t}\right)^{1-\nu_{1}}}{1-\nu_{1}} / \lambda_{t}^{C}$ which capture the worker's reservation wage, a function of unemployment compensation $b$ and the change in flow utility from employment compared to remaining unemployed.

\subsection{Equilibrium}

Financial markets clear in equilibrium. The risk-free asset is in zero net supply, and the household holds all the shares of the firms in retail and wholesale sectors. The goods market clearing condition is then given by:

$$
C_{t}+\kappa_{t} V_{t}+\frac{\Omega}{2}\left(\frac{\Pi_{t}}{\Pi}-1\right)^{2} Y_{t}=Y_{t}
$$

Intermediate goods market clearing implies

$$
Y_{t}=X_{t} N_{t} H_{t}^{\alpha}
$$

The competitive equilibrium in the economy consists of vacancy posting, $V_{t}^{\star} \geq 0$; hours per worker $H_{t}^{\star}$; multiplier, $\lambda_{t}^{V, \star} \geq 0$; consumption, $C_{t}^{\star}$; prices $\Pi_{t}^{\star}$ and $\psi_{t}^{\star}$; and nominal interest rate $R_{t}^{N \star}$; such that (i) $V_{t}^{\star}, H_{t}^{\star}$ and $\lambda_{t}^{V \text {, }}$ satisfy the intertemporal job creation condition (21) and the Kuhn-Tucker conditions (22), while taking the stochastic discount factor in equation (7) and the hours and wage equations (23) and (24) as given; (ii) $C_{t}^{\star}$, satisfies the intertemporal consumption-portfolio choice conditions (6); (iii) retail price setting satisfies optimality condition (17); (iv) the desired nominal rate follows either the deviations (1) or the shortfalls (2) rule; (v) the nominal policy rate satisfies the zero lower bound constraint (3), and (vi) the goods markets clear as in equations (25) and (26) 


\subsection{Calibration}

Our primary goal is examining the possible effects if monetary policymakers change from a symmetric deviations rule to a one-sided shortfalls rule. To ensure that our model provides a reasonable description of the U.S. economy prior to the policy change, we first assume that monetary policy follows the deviations rule and choose the parameters of our model to match key first- and second-moments in the labor market as well as inflation and nominal interest rates over the 1995-2019 sample period. Table 1 lists the resulting parameter values for the monthly-frequency calibration of our model. After calibrating the model, we then study the implications of moving from a deviations to shortfalls policy rule. We solve the model under both policy rules using a global solution method which accounts for the potential asymmetries in the policy reaction function as well as the zero lower bound and nonlinear dynamics in the labor market. ${ }^{5}$

Turning first to the parameters in the central bank's policy rule, we set the inflation target $\Pi^{*}$ to be consistent with the Federal Reserve's stated goal for price stability of 2 percent inflation. Following the work of Taylor (1993) and many others, we set the central bank's inflation response to a standard value $\phi_{\pi}=1.5$. In calibrating the unemployment response parameter $\phi_{u}$, we follow a conservative approach. From Equations (1) and (2), the quantitative significant of changing from a deviations rule to a shortfalls rule crucially depends on the calibration of the central bank's response to unemployment $\phi_{u}$. Recent work from Kahn and Palmer (2016) and Feroli et al. (2017) estimates the FOMC's implied policy reaction function in Equation (1) using the FOMC's quarterly Summary of Economic Projections. Using data prior to the new consensus statement, they find estimates for $\phi_{u}$ that range from -0.08 to -0.18 (at the monthly frequency of our model). Thus, in calibrating $\phi_{u}$, we take a conservative approach and set $\phi_{u}=-0.05$ under both the deviations and shortfalls rule. We assume monetary policymakers assess the long-run value of the unemployment rate $U^{*}$ to be 5 percent, which is close to the average rate of unemployment observed in our sample period for the U.S.

We use this same value to target an average unemployment rate of $5 \%$ in the model, first setting the separation rate $s$ to $3 \%$ based on the underlying labor market flows to take into account the two state (employed/unemployed) nature of the model (Petrosky-Nadeau and Valletta, 2020). This places a restriction on the average job finding rate $f$ and will pin down the value of worker's bargaining weight in wage setting $\eta$ given our calibration strategy

\footnotetext{
${ }^{5}$ Fernández-Villaverde et al. (2015) discusses the nonlinear dynamics present at the zero lower bound and Petrosky-Nadeau and Zhang (2017) study the nonlinear dynamics stemming from the matching frictions in the labor market.
} 
for the remaining parameters. This results in a value of $\eta=0.38$. This places the implied bargained weight in the middle of the range obtained in other work, from values as low as 0.05 in Hagedorn and Manovskii (2008) to a value of 0.72 in Shimer (2005).

We set the time discount factor, $\beta$, equal to $\exp (-0.5 / 1200)$ such that the annualized long-run neutral rate equals $0.5 \%$. This target is informed by estimates of the longer-run equilibrium real rate of interest from a variety approaches (Laubach and Williams, 2003; Lubik and Matthes, 2015; Christensen and Rudebusch, 2019). We set the elasticity of substitution between differentiated goods to $\omega=10$, such that the average markup $1 / \psi$ is about 11\%. This is broadly inline with microeconomic evidence presented in Basu and Fernald (1997). We choose the nominal price adjustment cost $\Omega$ such that the model generates the low volatility in inflation observed over the last two decades. To a first-order approximation (in which our quadratic-cost specification is observationally equivalent to a Calvo setting), our monthly calibrated value of $\Omega=450$ implies that firms adjust prices about every seven months, which is broadly consistent with the micro evidence in Nakamura and Steinsson (2008).

For the household preference parameters, we set the coefficient of relative risk aversion $\sigma=0.5$ which ensures a negative correlation between hours worked on the job and unemployment under our assumption of Nash bargained wages. The level parameter in the utility for leisure $\nu_{0}$ is set such that employed individuals spend on average 20 percent of their time endowment working. The curvature parameters $\nu_{1}$ is set to an individual labor supply elasticity of $\nu_{1}^{-1}\left(\frac{1}{H}-1\right)=1$ following the original contribution of Andolfatto (1996) and in line with estimates reviewed and discussed in Hall (2009). This results in $\nu_{1}=4$. Lastly, the utility associated with non-employment $\nu_{u}$ is set such that there is small gap between earnings and the reservation utility $Z / W H=0.85$. This is close to the value calibrated in Rudanko (2009) and estimated by Christiano, Eichenbaum and Trabandt (2016), resulting in a value of $\nu_{u}=0.24$.

We set the curvature parameter of the labor market matching function $\iota$ to 1.25 , the value in the original work of Haan, Ramey and Watson (2000) and applied in PetroskyNadeau, Zhang and Kuehn (2018). Silva and Toledo (2009) report that recruiting costs are 14 percent of quarterly pay per hire, or 0.4 months of pay per hire, based on data collected by PriceWaterhouseCoopers. We set $\kappa=\kappa_{0}+\kappa_{1}$ such that, on average, the cost of job creation $\kappa / q(\theta)=0.4 \times W H$. We then use the volatility of unemployment in the data to determine the relative importance of variable and fixed costs $\kappa_{0}$ and $\kappa_{1}$. A greater fixed 
Table 1: Calibrated Model Parameters

\begin{tabular}{|c|c|c|c|}
\hline Parameter & Notation & Value & Target/Source \\
\hline \multicolumn{4}{|l|}{ Preferences: } \\
\hline Discount factor & $\beta$ & $\exp (-0.5 / 1200)$ & $0.5 \%$ annualized real risk free rate \\
\hline Elast. of subst. btw. goods & $\omega$ & 10 & Average markup over marginal cost \\
\hline Utility: consumption & $\sigma$ & 0.5 & External \\
\hline Utility: leisure, level & $\nu_{0}$ & 0.74 & Average hours worked \\
\hline Utility: leisure, curvature & $\nu_{1}$ & 4 & Elasticity of labor supply \\
\hline Non-employment utility & $\nu_{u}$ & 0.24 & Reservation to wage ratio \\
\hline \multicolumn{4}{|l|}{ Price setting: } \\
\hline Price adjustment cost & $\Omega$ & 450 & Volatility of inflation \\
\hline \multicolumn{4}{|l|}{ Labor market: } \\
\hline Matching function: curvature & $\nu$ & 1.25 & Den Haan et al (2000) \\
\hline Worker bargaining weight & $\eta$ & 0.38 & Unemployment rate \\
\hline Vacancy cost & $\kappa_{0}$ & 0.03 & Recruiting costs to monthly wage \\
\hline Fixed hiring cost & $\kappa_{1}$ & 0.07 & Volatility of unemployment \\
\hline Job destruction rate & $s$ & 0.03 & Unemployment flow accounting $^{1}$ \\
\hline Unemployment benefits & $b$ & 0.12 & Replacement rate \\
\hline \multicolumn{4}{|l|}{ Monetary policy: } \\
\hline Weight on inflation & $\phi_{\pi}$ & 1.5 & Estimated on U.S. data ${ }^{2}$ \\
\hline Weight on unemp. gap & $\phi_{n}$ & -0.05 & Estimated on U.S. data ${ }^{2}$ \\
\hline Inflation target & $\pi^{*}$ & $1.02^{(1 / 12)}$ & FOMC target inflation \\
\hline Unemployment: natural rate & $U^{*}$ & 0.05 & Long run rate of unemployment \\
\hline \multicolumn{4}{|l|}{ Shock processes: } \\
\hline Technology: persistence & $\rho_{x}$ & 0.99 & U.S. labor productivity ${ }^{3}$ \\
\hline Technology: standard deviation & $\sigma_{x}$ & 0.008 & U.S. labor productivity ${ }^{3}$ \\
\hline Demand: persistence & $\rho_{\gamma}$ & 0.99 & \\
\hline Demand: standard deviation & $\sigma_{\gamma}$ & 0.02 & \\
\hline
\end{tabular}

Notes: We calibrate the model to monthly frequency. (1) based on the underlying labor market flows to take into account the two state (employed/unemployed) nature of the model (Petrosky-Nadeau and Valletta, 2020); (2) See the discussion in the text; (3) Non-farm business labor productivity. 
relative to variable cost increases the volatility of unemployment (Pissarides, 2009). This results in $\kappa_{0}=0.03$ and $\kappa_{1}=0.07$. Finally, with respect to the labor market, we set the value of unemployment benefit $b$ such that on average $b / W H=0.4$. This correspond to the typical earnings replacement rate across U.S. states reported by the Department of Labor (Department of Labor, 2019).

For the productivity process $X_{t}$, we set the persistence, $\rho_{x}$ to 0.99 and its conditional volatility, $\sigma_{x}=0.006$, to match the standard deviation of labor productivity in the data. ${ }^{6}$ For the demand shock process, we also set the persistence $\rho_{\gamma}=0.99$, which, at the monthly frequency of our model, is consistent with the quarterly estimated value of Ireland (2011). We calibrate the standard deviation of the demand shock process to match the empirical observed correlation between inflation and unemployment, which results in $\sigma_{\gamma}=0.013$.

Table 2 compares the implied quarterly moments in our model under the deviations policy rule to their empirical counterparts. Overall, our model is able to generally reproduce the first and second moments of unemployment, hours, inflation, and the nominal policy rate we observe in the data. The model closely matches the average and volatility of unemployment over the 1995-2019 period. Moreover, the model generally reproduces the low volatility of hours worked in the data and the negative correlation observed between unemployment and hours. Despite the policymakers in our model targeting two percent inflation, the presence of the zero lower bound and asymmetric fluctuations in the unemployment rate pushes average inflation under the deviations rule below two percent, similar to actual inflation over the last few decades. The model also matches the volatility of inflation as well as the model-implied correlation between unemployment and inflation (the reduced-form Phillips curve). While the model matches the average nominal interest rate quite well, our model slightly under predicts the volatility of the nominal policy rate and generates a bit too much correlation between the nominal policy rate and inflation. ${ }^{7}$ Overall, however, the results in Table 2 suggests that our model likely provides a reasonable, but highly stylized, description of the economy that we can use to conduct policy experiments.

\footnotetext{
${ }^{6}$ We measure the labor productivity as seasonally adjusted real average output per job in the nonfarm business sector (Series id: PRS85006163) from the Bureau of Labor Statistics. The sample is quarterly from 1951 to 2012. We detrend the series as the Hodrick-Prescott (1997, HP) filtered cyclical component of proportional deviations from the mean with a smoothing parameter of 1,600 .

${ }^{7}$ If we were to include an additional exogenous policy shock in the central bank's rule, the model's fit along these dimensions would likely improve. However, we eschew this additional feature in order to keep the model simple and because our focus is on the central bank's endogenous reaction to inflation and unemployment.
} 


\section{From Deviations to Shortfalls}

We now analyze the qualitative and quantitative implications of changing from a symmetric deviations rule in Equation (1) to the one-sided shortfalls rule in Equation (2), leaving all other parameters unchanged. First, we use the policy functions of the model to examine the qualitative effects on inflation and unemployment of adopting a shortfalls-stabilization rule. Then, we discuss the quantitative impacts of the new policy rule on the inflation, unemployment and the nominal policy rate. Shifting to a shortfalls rule not only affects longer-term average outcomes in the economy but also changes the entire distribution of inflation and unemployment outcomes. Finally, we examine the model-implied implications for the economy's reduced-form Phillips curve and its performance in the presence of the zero lower bound on nominal interest rates.

\subsection{Adopting a Shortfalls-Stabilization Rule: Intuition}

Figure 1: Policy Functions \& Impulse Responses to Demand Shocks

(a) Labor Market Tightness \& Demand

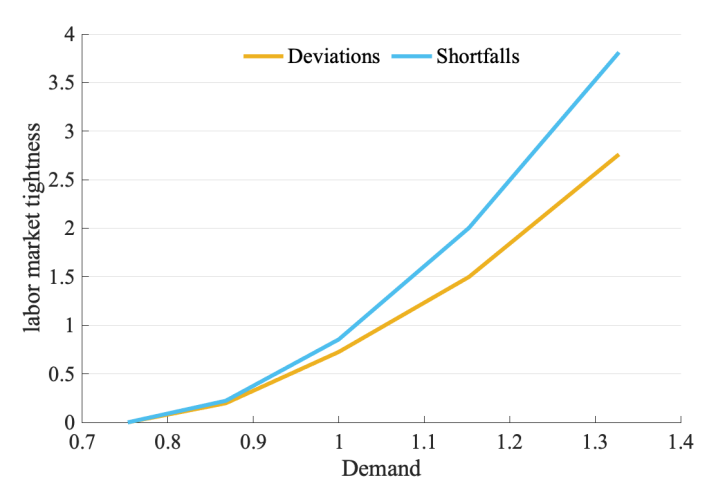

(c) IRF: Labor Market Tightness

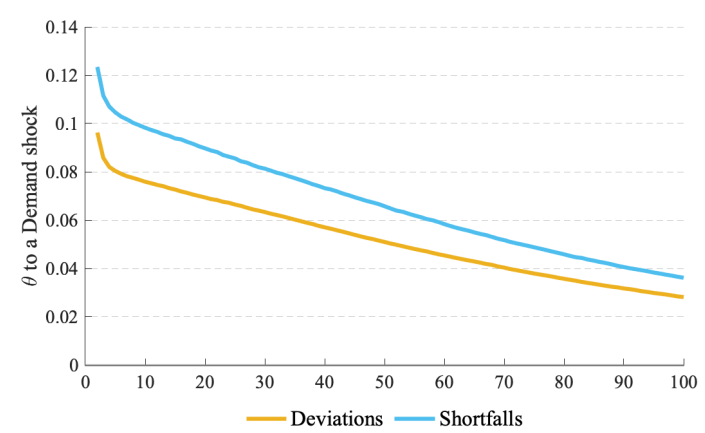

(b) Inflation \& Demand

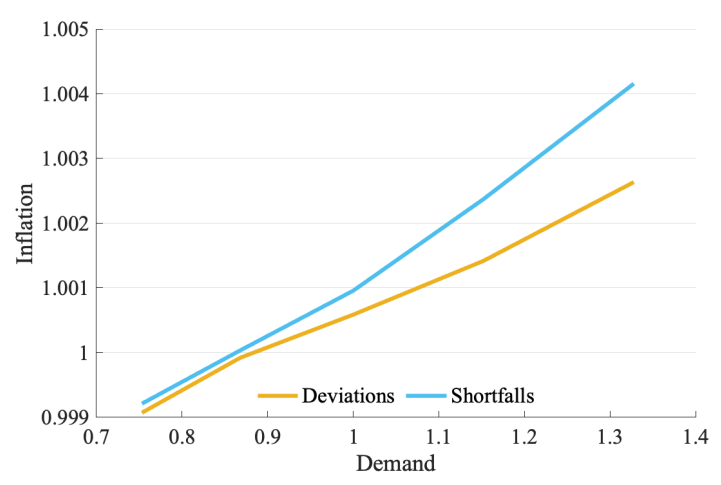

(d) IRF: Inflation

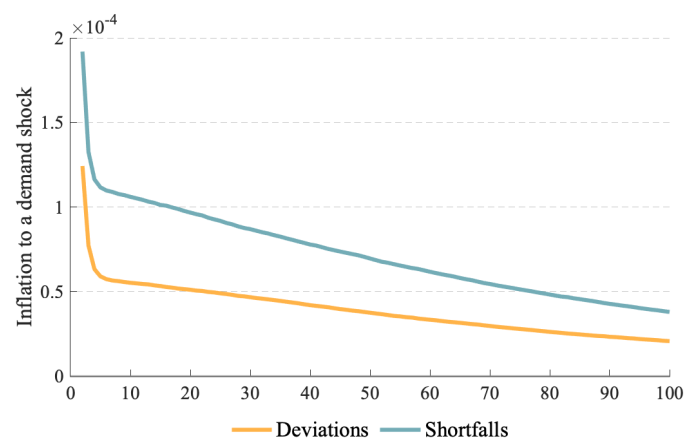

Note: Impulse responses to a one standard deviation innovation to demand, starting from the economy's stationary means for employment, productivity and demand and averaged across 5,000 simulations. 
While the difference in policymakers' behavior under the deviations or shortfalls rules in Equations (1) and (2) technically only becomes actualized when the unemployment rate falls below its longer-run value, changing to a shortfalls rule implies tighter labor markets and higher inflation in all states of the world. The top row Figure 1 plots the resulting policy functions for labor market tightness $\left(\theta_{t}\right)$ and the monthly gross inflation rate $\left(\Pi_{t}\right)$ as a function of the demand shock $\left(\exp \left(\gamma_{t}\right)\right)$ under both the deviations and shortfalls rule. ${ }^{8}$

Under a shortfalls-stabilization rule, forward-looking firms internalize that policymakers will not lean against a tight labor market. This expectation of more accommodative policy and higher demand in the future, in states of the world where unemployment falls below $U^{*}$, leads them to set higher prices and increases their demand for labor and hiring today. Figure 1a shows that this expansionary expectations effect of the shortfalls rule is stronger when the exogenous demand shock is above its longer run average (meaning the economy is in an expansion). Conversely, we also see diminishing differences in the policy functions between the two rules in low demand states as situations in which unemployment falls below $U^{*}$ are sufficiently far off in the future as to have a weakened effect on current hiring and pricing decisions. The impulse responses to a demand shock, in the bottom row of Figure 1, also illustrate the increased slope of the labor market tightness and inflation policy functions under the shortfalls stabilization rule. Following a positive demand shocks, labor markets tighten more and firms set higher prices under the one-sided shortfalls rule.

The policy functions over values of exogenous productivity in the top row of Figure 2 also highlight this effect where we observe tighter labor markets and higher inflation for all levels of productivity. Moreover, as monetary policy no longer works to offset states of the world where unemployment falls below $U^{*}$, there is a flattening of the negative slope of inflation to productivity. That is, increases in productivity have a smaller downward pressure on price inflation under the shortfalls rule. The policy functions and impulse responses (bottom row of Figure 2) show that labor market tightness and inflation move in opposite directions in response to a change in productivity. Since unemployment is inversely related to labor market tightness, demand shocks need to be more important for driving aggregate fluctuations for the model to reproduce the negative relationship between unemployment and inflation that we observe in the data. However, the differences between the shortfalls and deviations rules in response to productivity shocks highlights that the FOMC's new employment objective may affect the economy's response to many types of shocks hitting the economy (including

\footnotetext{
${ }^{8}$ To produce these figures, we set employment $N_{t}$ (the endogenous state variable in our model) equal to its longer-run value. Appendix Figure A.2 plots the policy functions for labor market tightness, inflation and hours worked on the job over employment and, separately, productivity and demand.
} 
Figure 2: Policy Functions \& Impulse Responses to Productivity Shocks

(a) Labor Market Tightness \& Productivity

(b) Inflation \& Productivity

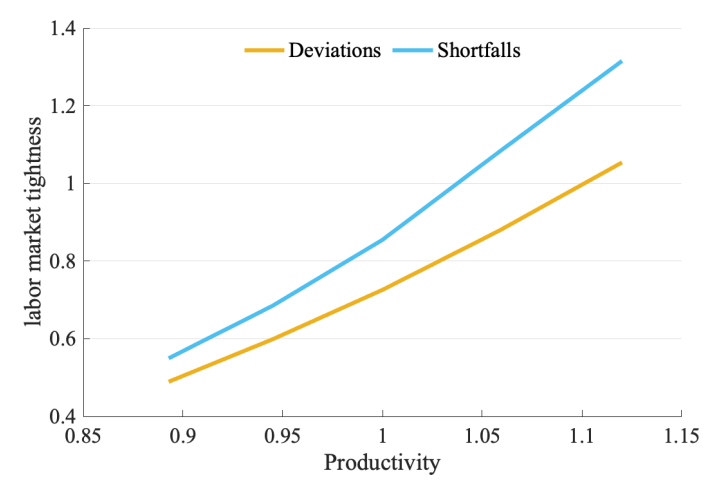

(c) IRF: Labor Market Tightness

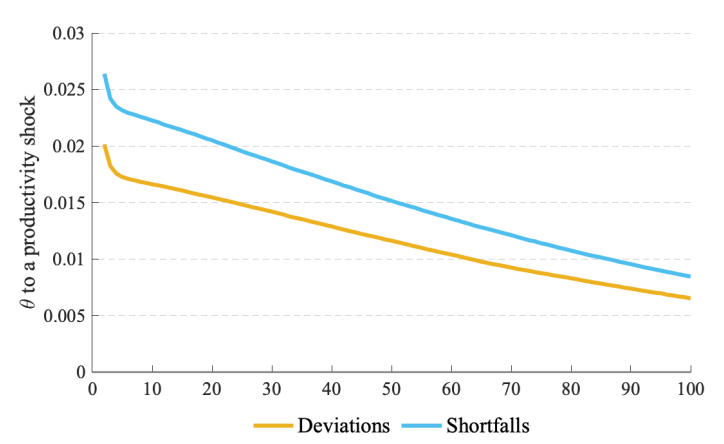

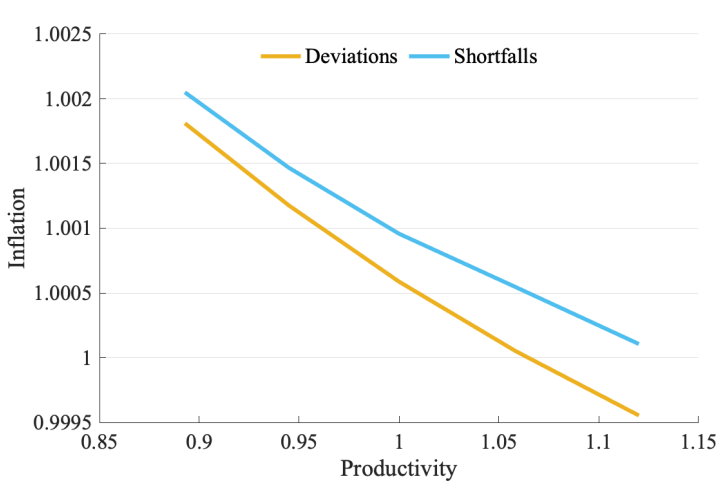

(d) IRF: Inflation

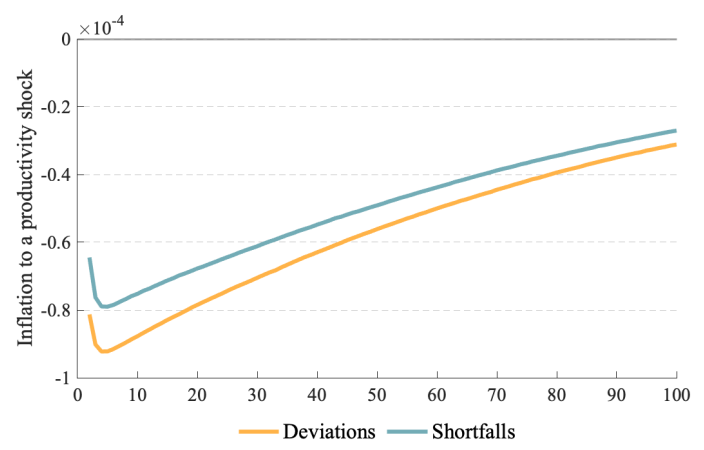

Note: Impulse responses to a one standard deviation innovation to productivity, starting from the economy's stationary means for employment, productivity and demand and averaged across 5,000 simulations. 
Table 2: Empirical and Model-Implied Moments

\begin{tabular}{|c|c|c|c|}
\hline & Data & Deviations Rule & Shortfalls Rule \\
\hline \multicolumn{4}{|l|}{ Mean (\%): } \\
\hline$U$ & 5.7 & 5.3 & 5.1 \\
\hline$\pi$ & 1.8 & 1.9 & 2.4 \\
\hline$R$ & 2.5 & 2.6 & 3.1 \\
\hline \multicolumn{4}{|c|}{ Standard deviation: } \\
\hline$\sigma(U)$ & 0.08 & 0.08 & 0.09 \\
\hline$\sigma(\pi)$ & 0.13 & 0.13 & 0.14 \\
\hline$\sigma(R)$ & 0.50 & 0.23 & 0.23 \\
\hline$\sigma(H)$ & 0.01 & 0.02 & 0.02 \\
\hline \multicolumn{4}{|c|}{ Cross. correlation: } \\
\hline $\operatorname{corr}(U, \pi)$ & -0.23 & -0.24 & -0.36 \\
\hline $\operatorname{corr}(U, H)$ & -0.67 & -0.76 & -0.73 \\
\hline $\operatorname{corr}(R, \pi)$ & 0.32 & 0.68 & 0.69 \\
\hline $\operatorname{corr}(R, U)$ & -0.82 & -0.84 & -0.89 \\
\hline
\end{tabular}

Notes: Details on the sources and transformation applied to the U.S data are available in Appendix Section A. The empirical sample period is 1995Q1-2019Q4. Model moments are computed on 10,000 simulations of 300 periods, equal to the number of months in the data sample and then average over three period for a quarterly frequency. Empirical and model data are converted to proportional deviations and Hodrick-Prescott filtered before computing second moments.

shocks we do not consider in our model).

\subsection{Quantitative Impacts on Inflation \& Unemployment}

Moving to a shortfalls stabilization rule can have quantitatively significant effects on both the business-cycle properties and the longer-run outcomes for the economy. The last column of Table 2 reports the effect on first and second moments of interest of adopting the shortfalls-stabilization rule in Equation (2), keeping all other parameters fixed to their calibrated values. The more accommodative response to low unemployment under the shortfalls rule raises average inflation by roughly 50 basis points, and lowers the average unemployment rate from 5.3 percent to 5.1 percent. Despite only changing the policymaker's response to tight labor markets, the adoption of a shortfalls-stabilization rules generates higher inflation and tighter labor markets on average.

While changing to a shortfalls rule has only a modest impact on the volatility of inflation and unemployment, we see a significant impact on their respective distributions. The top 
Figure 3: Model-Implied Stationary Distributions Under Deviations \& Shortfalls Rules
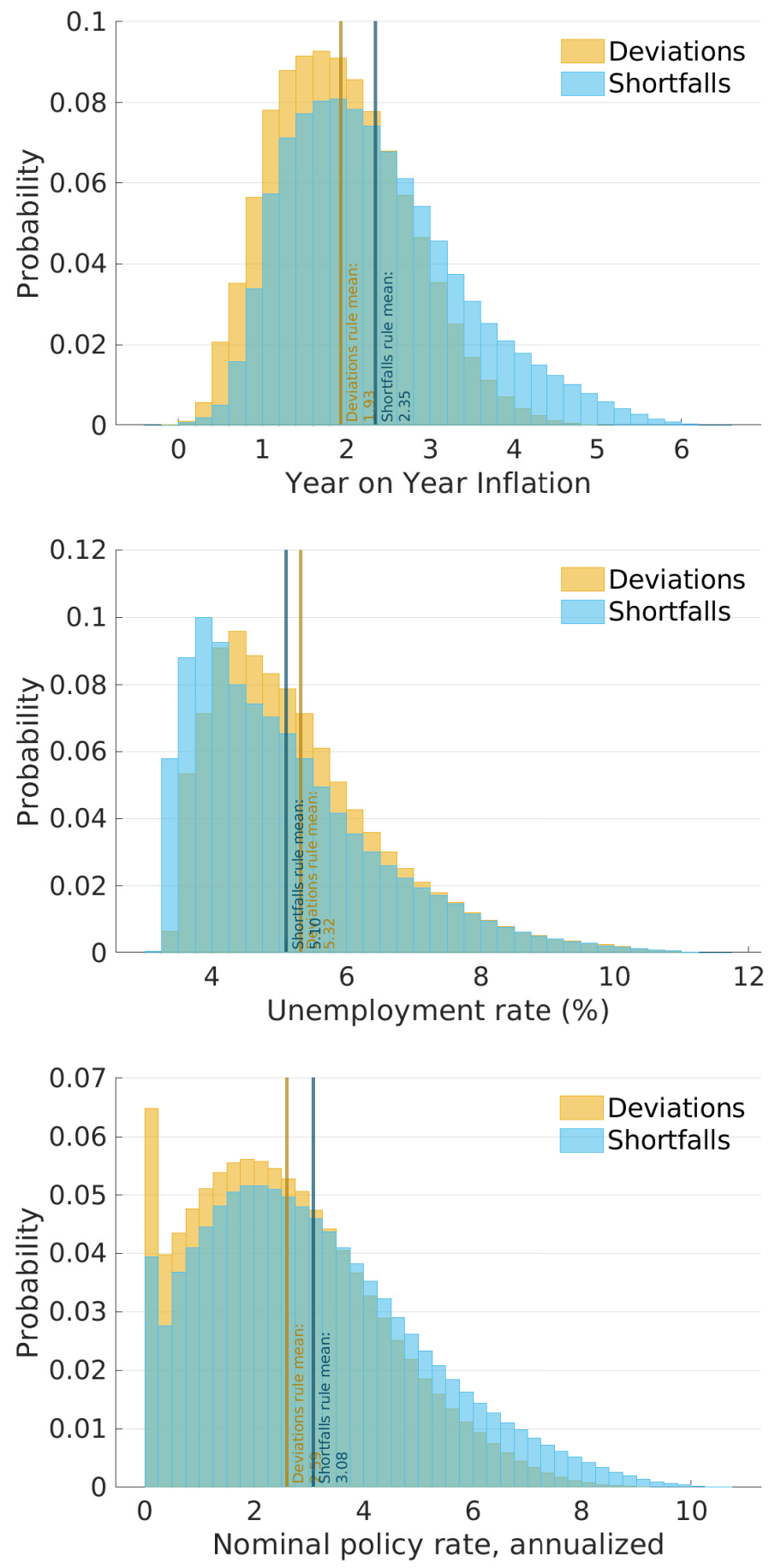

Note: Model distributions obtain from 10,000 simulations of 300 periods, equal to the number of months in the data sample. Vertical lines correspond to sample means of the respective variables. 
Figure 4: Model-Implied Joint Distributions of Inflation \& Unemployment

(a) Deviations Rule

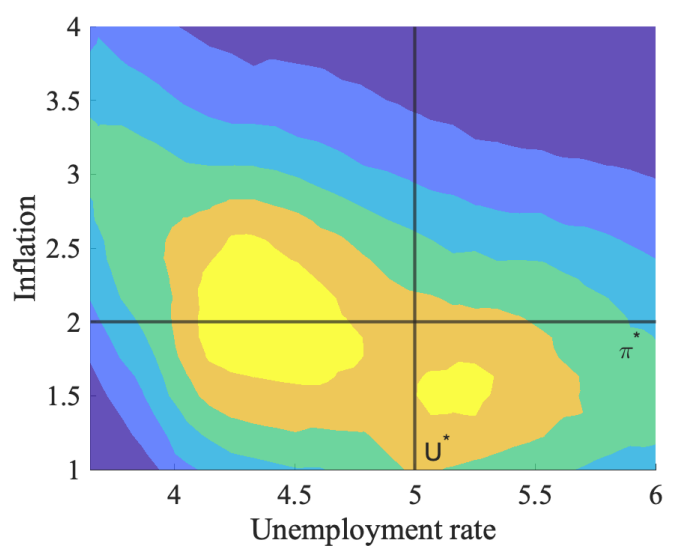

(b) Shortfalls-Stabilization Rule

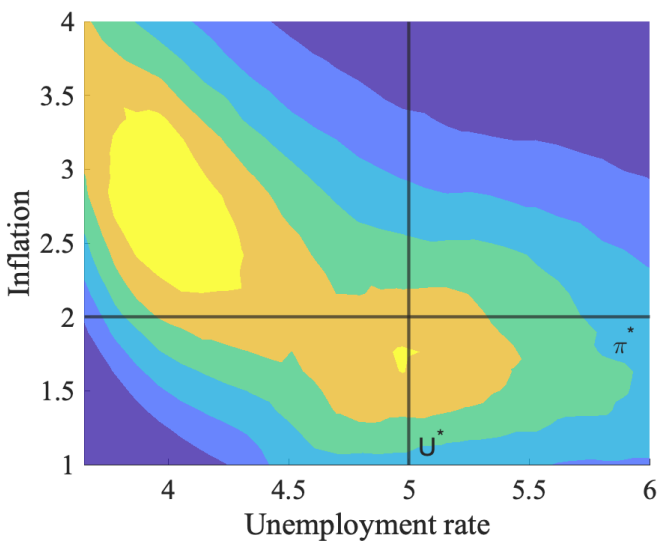

Note: Model distributions obtained from 10,000 simulations of 300 periods.

two panels of Figure 3 reports the model's simulated distributions of inflation and unemployment under both the deviations (orange) and shortfalls (blue) rules. Changing to a one-sided shortfalls rule increases the likelihood of robust expansions with higher inflation and lower unemployment. We see a pronounced decline in the probability of inflation outcomes below $1 \%$ while the realizations of inflation above $3 \%$ become more likely. Specifically, the frequency of inflation below $1 \%$ declines from $12 \%$ to $6 \%$ and the frequency of inflation above $3 \%$ increases from $10 \%$ to $24 \%$ when adopting the shortfalls-stabilization rule. With respect to the labor market, our model implies that low unemployment outcomes (4\% or below) become more frequent under the shortfalls rule while we see little change in the frequency of high unemployment rates above $7 \%$. Specifically, the frequency of unemployment above $7 \%$ is about $11 \%$ under both the deviations and shortfalls rules while the frequency of unemployment below $4 \%$ increases from $13 \%$ to $25 \%$ when adopting the shortfalls-stabilization rule. Thus, a shortfalls rule does not prevent high unemployment rates during recessions but instead ensures a more rapid return to full employment in a recovery and more sustained periods of low unemployment during expansions.

\subsubsection{Implications for the Philipps Curve}

As we discussed, adopting a shortfalls-stabilization rule results in higher inflation and more hiring on average as well as increasing the likelihood of robust expansions with higher inflation and lower unemployment. Thus, we see a shift in the systematic relationship between inflation and unemployment in the model if policymakers adopt a shortfalls-only rule.

In terms of the reduced-form Philipps curve, a change in the monetary policy rule toward 
Figure 5: Recovery From a Zero Lower Bound Episode Under Deviations \& Shortfalls Rules

(a) Unemployment

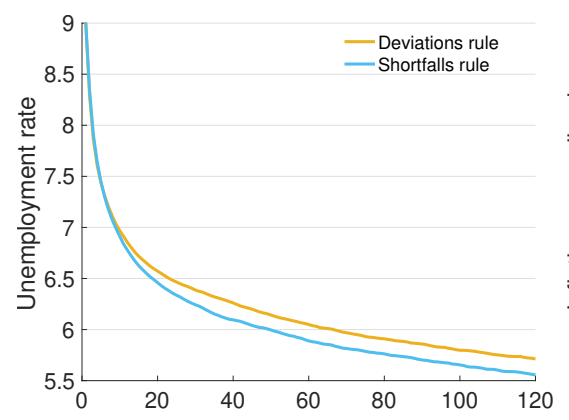

(b) Inflation

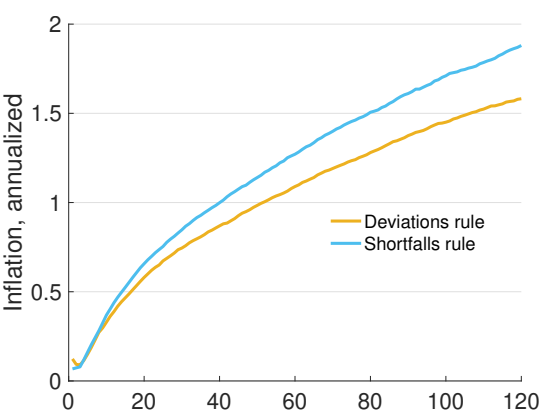

(c) Nonimal policy rate

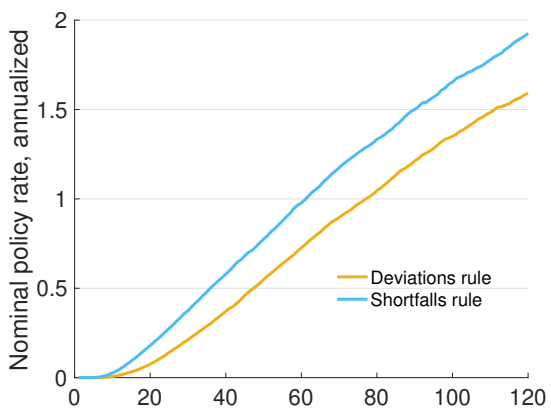

Note: Average paths from an initial state of $9 \%$ unemployment, demand at the 5 th percentile of its ergodic distribution, productivity at the 95 th percentile of its distribution, and no additional innovations.

only stabilizing employment shortfalls increases the intercept and results in a steeper slope. Figure 4 plots the joint density of inflation and unemployment under the deviations rule in panel (a) and shortfalls rule in (panel (b)). When policymakers follow the deviations rule, the economy spends a large fraction of time with unemployment below its longer-run rate (lighter colors denote more likely outcomes). However, these periods of low unemployment are often associated with inflation either above or below the central bank's two percent objective. In contrast, under a shortfalls-stabilization rule, periods of low unemployment are typically accompanied with inflation somewhat above two percent. Quantitatively, the Phillips curve steepens under the shortfalls rule as Table 2 shows that the correlation between inflation and unemployment falls from -0.23 to -0.36 if policymakers no longer try and lean against a tight labor market.

\subsubsection{A Shortfalls Rule Helps Alleviate the Zero Lower Bound Constraint}

These combined effects on inflation and unemployment under the shortfalls rule also help alleviate the contractionary effects of the zero lower bound in two ways. First, the zero lower bound constrains policymakers less often under a shortfalls rule. The last column of Table 2 shows that the higher inflation and employment on average leads to a 50 basis point increase in the average nominal interest rate. Higher average policy rates imply that policymakers become constrained less often under a shortfalls rule, which the bottom panel of Figure 3 illustrates. Specifically, the zero lower bound binds about half as often under the shortfalls rule when compared with the deviations rule (the frequency of zero policy rates falls from $6.5 \%$ to $4 \%$ under the shortfalls rule).

Second, conditional on hitting the zero lower bound, the expectations of higher inflation 
and lower unemployment imply a quicker recovery from a zero lower bound episode. Figure 5 plots the average path of the economy to its stationary mean (assuming no additional innovations) starting from a state in which the economy is at the lower bound. That is, demand is at the 5 th percentile of its ergodic distribution and expected to rise, productivity is at the 95th percentile of its distribution and expected to decline, and unemployment is elevated at $9 \%$. The figure shows there is a modest improvement in the path for unemployment under the shortfalls rule. Inflation, which returns to target over the period shown

here under the shortfalls rule, just exceeds $1.5 \%$ under the deviations rule. With these more favorable outcomes, the nominal policy rate exits the zero lower bound earlier than under the deviations rule.

\section{Conclusion}

The Federal Open Market Committee recently revised its consensus statement indicating it seeks "over time to mitigate shortfalls of employment from the Committee's assessment of its maximum level ..." In contrast, the previous statement cited a desire to stabilize "deviations" of employment from its maximum level. This paper analyzed the possible inflation and employment effects of this policy change using a theoretical model which combines frictional labor markets, nominal rigidities, and the zero lower bound.

A monetary policy which stabilizes "shortfalls" rather than "deviations" of employment from its maximum level affects firm price setting and hiring behavior in all states of the world. Since policymakers will not lean against a tight labor market under a shortfalls-stabilization rule, the expectation of more accommodative policy leads forward-looking firms to set higher prices and increase hiring due to the higher expected future demand. The higher prices and increased hiring under the shortfalls-stabilization rule leads to higher inflation and employment, on average. In addition to these changes in average outcomes for the economy, changing to a one-sided shortfalls rule increases the likelihood of robust expansions with higher inflation and lower unemployment and results in a steeper reduced-form Phillips curve.

The model shows that a policy rule which only offsets employment shortfalls also increases the average nominal policy rate and reduces the frequency of zero lower bound episodes. Moreover, it produces better outcomes during a ZLB episode due to the expectation of a more accommodative policy in the future. This suggest that the reinterpretation of the employment mandate complements and reinforces the desired policy outcomes of the FOMC's flexible inflation targeting framework. 


\section{References}

Albertini, Julien, and Arthur Poirier. 2015. "Unemployment Benefit Extension at the Zero Lower Bound." Review of Economic Dynamics, 18(4): 733-751.

Altig, David, Jeff Fuhrer, Marc P. Giannoni, and Thomas Laubach. 2020. "The Federal Reserve's Review of Its Monetary Policy Framework: A Roadmap." Board of Governors of the Federal Reserve System FEDS Notes.

Amano, Robert, Stefano Gnocchi, Sylvain Leduc, and Joel Wagner. 2020. "Average Is Good Enough: Average-Inflation Targeting and the ELB." Federal Reserve Bank of San Francisco Working Paper Series 2020-21.

Andolfatto, David. 1996. "Business Cycles and Labor Market Search." American Economic Review, 86: 112-132.

Basu, Susanto, and John G. Fernald. 1997. "Returns to Scale in U.S. Production: Estimates and Implications." Journal of Political Economy, 105(2): 249-283.

Blanchard, Olivier, and Jordi Galí. 2010. "Labor Markets and Monetary Policy: A NewKeynesian Model With Unemployment." American Economic Journal: Macroeconomics, $2(2): 1-30$.

Christensen, Jens H. E., and Glenn D. Rudebusch. 2019. "A New Normal for Interest Rates? Evidence from Inflation-Indexed Debt." The Review of Economics and Statistics, 101(5): 933-949.

Christiano, Lawrence J., Martin S. Eichenbaum, and Mathias Trabandt. 2016. "Unemployment and Business Cycles." Econometrica, 84(4): 1523-1569.

Coibion, Olivier, Yuriy Gorodnichenko, and Johannes Wieland. 2012. "The Optimal Inflation Rate in New Keynesian Models: Should Central Banks Raise Their Inflation Targets in Light of the Zero Lower Bound?" The Review of Economic Studies, 79(4): 13711406.

Cooley, Thomas, and Vincenzo Quadrini. 1999. "A Neoclassical Model of the Phillips Curve Relation." Journal of Monetary Economics, 44: 165-193.

Davig, Troy, and Eric M Leeper. 2006. "Endogenous Monetary Policy Regime Change." National Bureau of Economic Research Working Paper 12405.

Department of Labor. 2019. "Comparison of State Unemployment Laws 2019." 
Dolado, Juan J., Ramon Maria-Dolores, and Manual Naveira. 2005. "Are MonetarPolicy Reaction Function Assymetric? The Role of Nonlinearity in the Phillips curve." European Economic Review, 49(2): 485-503.

Faia, Ester. 2008. "Optimal monetary policy rules with labor market frictions." Journal of Economic Dynamics and Control, 32(5): 1600-1621.

Fernández-Villaverde, Jesús, Grey Gordon, Pablo Guerrón-Quintana, and Juan F. Rubio-Ramírez. 2015. "Nonlinear adventures at the zero lower bound." Journal of Economic Dynamics and Control, 57: 182-204.

Feroli, Michael, David Greenlaw, Peter Hooper, Frederic Mishkin, and Amir Sufi. 2017. "Language after liftoff: Fed communication away from the zero lower bound." Research in Economics, 71(3): 452-490.

Gertler, Mark, and Antonella Trigari. 2009. "Unemployment Fluctuations with Staggered Nash Wage Bargaining." Journal of Political Economy, 117(1): 38-86.

Gertler, Mark, Luca Sala, and Antonella Trigari. 2008. "An Estimated Monetary DSGE Model with Unemployment and Staggered Nominal Wage Bargaining." Journal of Money, Credit, and Banking, 40: 1713-1764.

Gust, Christopher, David López-Salido, and Steve Meyer. 2017. "Asymmetric monetary policy and the effective lower bound." Research in Economics, 71(3): 441-451. Special issue on Macroeconomics.

Haan, Wouter Den, Garey Ramey, and Joel Watson. 2000. "Job Destruction and Propagation of Shocks." American Economic Review, 90: 482-498.

Hagedorn, Marcus, and Iourii Manovskii. 2008. "The Cyclical Behavior of Equilibrium Unemployment and Vacancies Revisited." American Economic Review, 98(4): 1692-1706.

Hall, Robert E. 2009. "Reconciling Cyclical Movements in the Marginal Value of Time and the Marginal Product of Labor." Journal of Political Economy, 117(2): 281-323.

Hall, Robert E., and Paul R. Milgrom. 2008. "The Limited Influence of Unemployment on the Wage Bargain." American Economic Review, 98(4): 1653-74.

Ireland, Peter N. 2011. "A New Keynesian Perspective on the Great Recession." Journal of Money, Credit, and Banking, 43(1): 31-54. 
Kahn, George, and Andrew Palmer. 2016. "Monetary Policy at the Zero Lower Bound: Revelations from the FOMC's Summary of Economic Projections." Economic Review, 102(1): 5-37.

Krause, Michael, and Thomas Lubik. 2007. "The (Ir)relevance of Real Wage Rigidity in the New Keynesian Model with Search Frictions." Journal of Monetary Economics, 54: 706-727.

Laubach, Thomas, and John C. Williams. 2003. "Measuring the Natural Rate of Interest." The Review of Economics and Statistics, 85(4): 1063-1070.

Lubik, Thomas, and Christian Matthes. 2015. "Calculating the Natural Rate of Interest: A Comparison of Two Alternative Approaches." Federal Reserve Bank of Richmond Economic Brief EB15-10.

Mertens, Thomas M., and John C. Williams. 2019. "Monetary Policy Frameworks and the Effective Lower Bound on Interest Rates." AEA Papers and Proceedings, 109: 427-32.

Moscarini, Giuseppe, and Fabien Postel-Vinay. 2017. "The Job Ladder: Inflation vs. Reallocation." Working Paper.

Nakamura, Emi, and Jón Steinsson. 2008. "Five Facts about Prices: A Reevaluation of Menu Cost Models*." The Quarterly Journal of Economics, 123(4): 1415-1464.

Nessen, Marianne, and David Vestin. 2005. "Average Inflation Targeting." Journal of Money, Credit and Banking, 37(5): 837-63.

Orphanides, Athanasios, and Volker Wieland. 2000. "Inflation zone targeting." European Economic Review, 44(7): 1351-1387.

Petrosky-Nadeau, Nicolas, and Lu Zhang. 2017. "Solving the Diamond-MortensenPissarides model accurately." Quantitative Economics, 8(2): 611-650.

Petrosky-Nadeau, Nicolas, and Robert G. Valletta. 2020. "Unemployment Paths in a Pandemic Economy." Federal Reserve Bank of San Francisco Working Paper 2020-18.

Petrosky-Nadeau, Nicolas, Lu Zhang, and Lars-Alexander Kuehn. 2018. "Endogenous Disasters." American Economic Review, 108(8): 2212-45.

Pissarides, Christopher A. 2009. "The Unemployment Volatility Puzzle: Is Wage Stickiness the Answer?" Econometrica, 77(5): 1339-1369. 
Powell, Jerome H. 2021. "Getting Back to a Strong Labor Market." Remarks at the Economic Club of New York.

Rudanko, Leena. 2009. "Labor market dynamics under long-term wage contracting." Journal of Monetary Economics, 56(2): 170 - 183.

Sala, Luca, Ulf Soderstrom, and Antonella Trigari. 2008. "Monetary Policy Under Uncertainty in an Estimated Model with Labor Market Frictions." Journal of Monetary Economics, 55: 983-1006.

Shimer, Robert. 2005. "The Cyclical Behavior of Equilibrium Unemployment and Vacancies." American Economic Review, 95(1): 25-49.

Silva, José Ignacio, and Manuel Toledo. 2009. "Labor Turnover Costs and the Cyclical Behavior of Vacancies and Unemployment." Macroeconomic Dynamics, 13: 76-96.

Surico, Paolo. 2007. "The Fed's monetary policy rule and U.S. inflation: The case of asymmetric preferences." Journal of Economic Dynamics and Control, 31(1): 305-324.

Taylor, John B. 1993. "Discretion Versus Policy Rules in Practice." Carnegie-Rochester Conference Series on Public Policy, 39: 195-214.

Walsh, Carl. 2005. "Labor Market Search, Sticky Prices, and Interest Rate Policies." Review of Economic Dynamics, 8: 829-849. 


\section{APPENDIX}

\section{A Data}

The sources for the empirical data, and their transformations, are as follows.

Unemployment rate: Unemployment rate for the civilian population, 16 years old and over, monthly, seasonally adjusted. Obtained from FRED II, series ID UNRATE. The monthly series spans from Jan. 1948 to March 2021. Converted to quarterly by three-month averaging. The raw series is plotted in Figure A.1a.

Fed Funds rate: Effective Federal Funds rate, percent, monthly, NSA. Obtained from FRED II, series ID FEDFUNDS. The monthly series spans from July 1954 to Jan. 2021. Converted to quarterly by three-month averaging. The raw series is plotted in Figure A.1c.

Inflation: The underlying price level series is the overall PCE Chain-type Price Index (2012=100), monthly and seasonally adjusted, obtained from FRED II, series ID PCEPI. The series spans from Jan. 1959 to Feb. 2021. For comparison we also use the core PCE Chain-type Price Index $(2012=100)$, monthly and seasonally adjusted, obtained from FRED II, series ID PCEPILFE. The series are used to construct the following measures of price inflation, the third being the baseline reported in the paper:

(a) Month on month inflation, averaged to quarterly: We calculate the month on month change in the price index, annualize the rate, and convert to a quarterly frequency using 3 month averages.

(b) Quarter on quarter inflation: We convert the monthly price index to a quarterly frequency using 3 month averages, then calculate the quarter on quarter change and annualize the rate.

(c) Year on year inflation: The monthly price index is converted to a quarterly frequency using 3 month averages. Then the year on year inflation is calculated using the quarterly series.

Key moments for the constructed inflation series, over three separate time frames, are reported in Table A.1. 


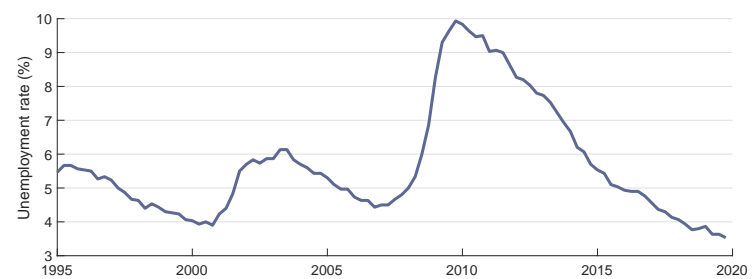

(a) Unemployment rates

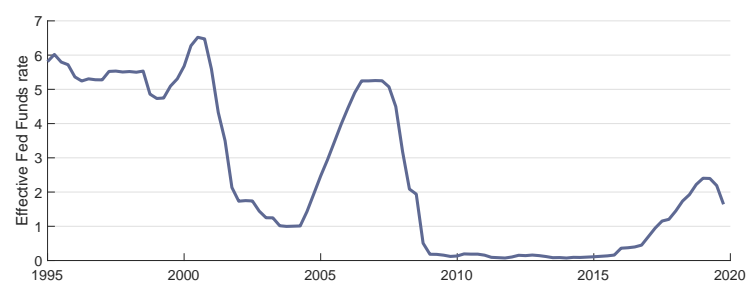

(c) Nonimal policy rate

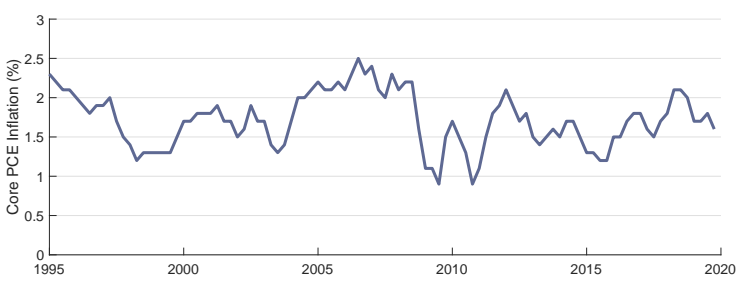

(b) Inflation

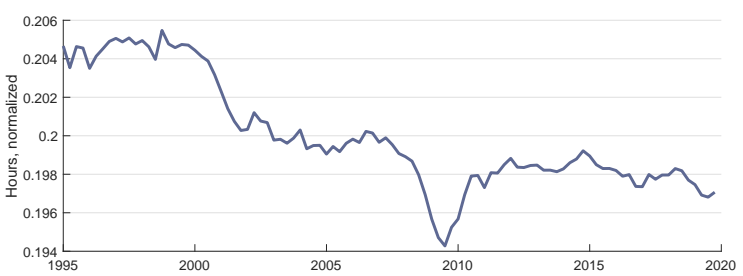

(d) Hours worked on the job

Figure A.1: U.S. data Note:

Hours worked: We use actual hours worked on the job constructed from the CPS micro data. The monthly series spans Jan. 1983 to March 2021 is seasonal adjusted with the Census Bureau's X-12 procedure, and converted to quarterly by three-month averaging. The raw series is plotted in Figure A.1d. 
Table A.1: U.S. PCE and core PCE inflation, first and second moments

\begin{tabular}{|c|c|c|c|c|c|c|}
\hline & \multicolumn{3}{|c|}{ PCE Iinflation } & \multicolumn{3}{|c|}{ Core PCE inflation } \\
\hline & $\pi(1)$ & $\pi(2)$ & $\pi(3)$ & $\pi(1)$ & $\pi(2)$ & $\pi(3)$ \\
\hline \multicolumn{7}{|c|}{ 1984Q1 to 2019Q4 } \\
\hline$E(\pi)$ & 2.25 & 2.23 & 2.25 & 2.26 & 2.25 & 2.28 \\
\hline$\sigma(\pi)$ & 0.92 & 0.82 & 0.62 & 0.55 & 0.30 & 0.15 \\
\hline $\operatorname{corr}(U, \pi)$ & -0.07 & -0.13 & -0.27 & -0.10 & -0.21 & -0.41 \\
\hline $\operatorname{corr}(H, \pi)$ & - & - & - & - & - & - \\
\hline $\operatorname{corr}(R, \pi)$ & 0.06 & 0.10 & 0.34 & 0.11 & 0.24 & 0.47 \\
\hline \multicolumn{7}{|c|}{ 1995Q1 to 2019Q4 } \\
\hline$E(\pi)$ & 1.82 & 1.80 & 1.80 & 1.72 & 1.71 & 1.72 \\
\hline$\sigma(\pi)$ & 0.93 & 1.00 & 0.70 & 0.61 & 0.28 & 0.13 \\
\hline $\operatorname{corr}(U, \pi)$ & -0.02 & -0.10 & -0.23 & -0.06 & -0.18 & -0.45 \\
\hline $\operatorname{corr}(H, \pi)$ & -0.06 & -0.01 & 0.08 & -0.01 & 0.10 & 0.25 \\
\hline $\operatorname{corr}(R, \pi)$ & 0.05 & 0.09 & 0.32 & 0.11 & 0.26 & 0.51 \\
\hline \multicolumn{7}{|c|}{ 1984Q1 to 2007Q4 } \\
\hline$E(\pi)$ & 2.62 & 2.59 & 2.60 & 2.59 & 2.58 & 2.61 \\
\hline$\sigma(\pi)$ & 0.95 & 0.81 & 0.33 & 0.47 & 0.28 & 0.14 \\
\hline $\operatorname{corr}(U, \pi)$ & -0.11 & -0.20 & -0.44 & -0.12 & -0.25 & -0.37 \\
\hline $\operatorname{corr}(H, \pi)$ & - & - & - & - & - & - \\
\hline $\operatorname{corr}(R, \pi)$ & 0.03 & 0.13 & 0.40 & 0.06 & 0.20 & 0.45 \\
\hline \multicolumn{7}{|c|}{ 1995Q1 to 2007Q4 } \\
\hline$E(\pi)$ & 2.11 & 2.07 & 2.04 & 1.84 & 1.82 & 1.82 \\
\hline$\sigma(\pi)$ & 1.00 & 0.94 & 0.27 & 0.54 & 0.22 & 0.10 \\
\hline $\operatorname{corr}(U, \pi)$ & 0.002 & -0.20 & -0.36 & -0.007 & -0.13 & -0.32 \\
\hline $\operatorname{corr}(H, \pi)$ & -0.11 & 0.01 & 0.09 & 0.02 & 0.26 & 0.13 \\
\hline $\operatorname{corr}(R, \pi)$ & -0.02 & 0.11 & 0.35 & 0.01 & 0.16 & 0.47 \\
\hline
\end{tabular}

Notes: Inflation 1 through 3 are defined as : (1) month on month inflation, annualized and averaged quarterly; (2) quarter on quarter inflation, annualized ; and (3) year on year inflation, quarterly price index. The underlying price level series are the PCE and core PCE Chain-type Price Indices $(2012=100)$, monthly and seasonally adjusted, obtained from FRED II, series ID PCEPI and PCEPILF respectively. The series spans from Jan. 1959 to Feb. 2021. 
Figure A.2: Model economy policy function for labor market tightness, hours per worker and inflations under deviation and shortfall policy rules

(a) Labor market tightness and productivity

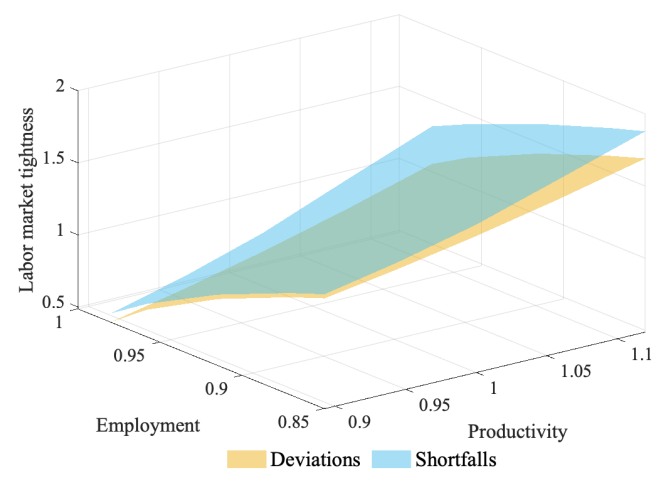

(c) Inflation and productivity

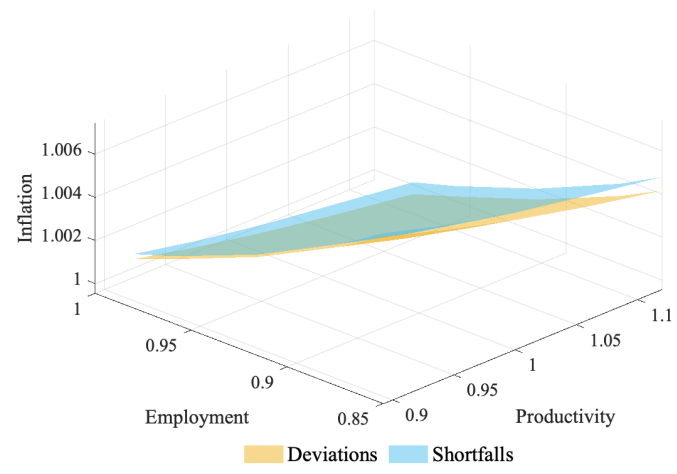

(e) Hours per worker and productivity

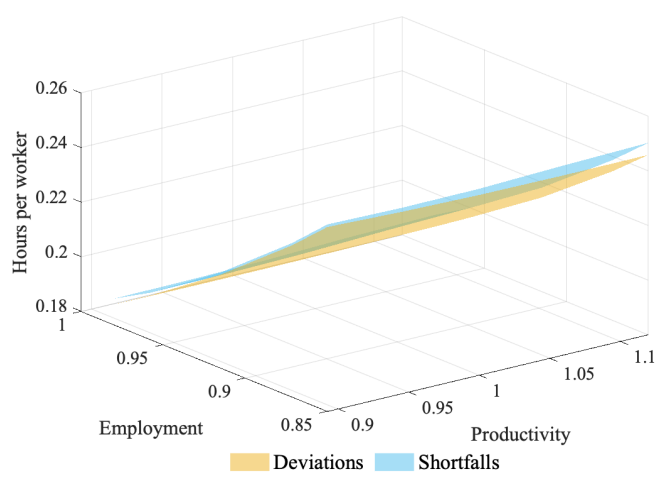

(b) Labor market tightness and demand

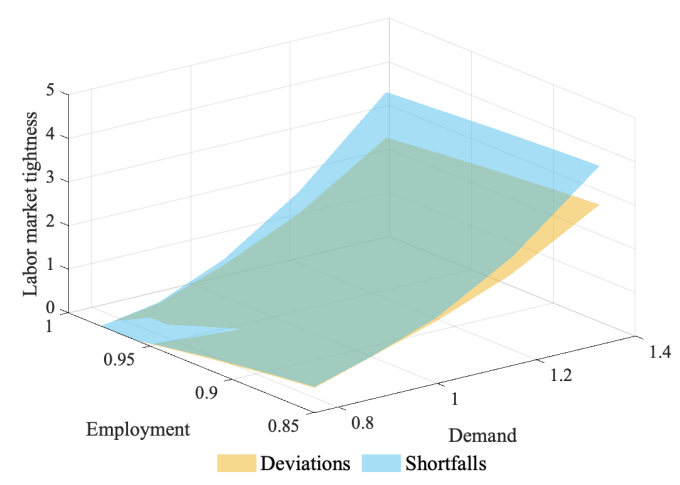

(d) Inflation and demand

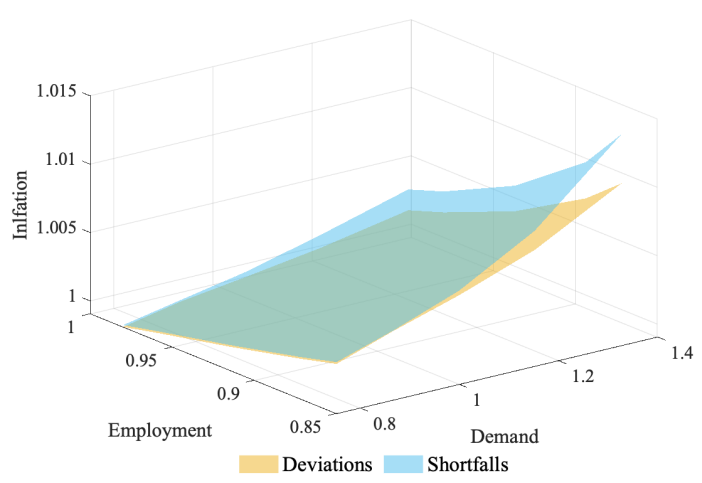

(f) Hours per worker and demand

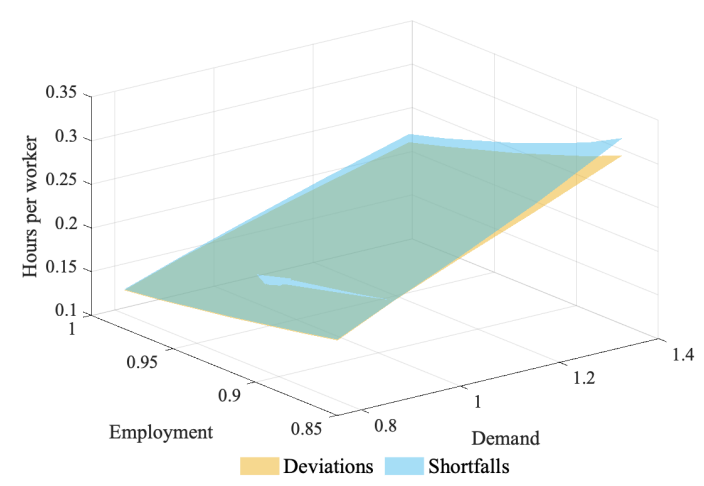




\section{B Detailed Derivations}

\section{B.1 Full model}

\section{B.1.1 Wholesale sector firm and worker marginal values and match surplus}

Write the firm's value function as

$$
S_{t}^{w}=\psi_{t} X_{t} N_{t} H_{t}^{\alpha}-W_{t} N_{t} H_{t}-\kappa_{t} V_{t}+E_{t}\left[M_{t, t+1} S_{t+1}^{w}\right]+\lambda_{t}^{V} q\left(\theta_{t}\right) V_{t}
$$

The optimality condition of this problem guarantees that

$$
S_{V t}^{w} \equiv \frac{\partial S_{t}^{w}}{\partial V_{t}}=0
$$

The marginal value of a hired worker is obtained from differentiating the firm's value function with respect to $N_{t}$, using the law of motion for employment and the definition of the household's stochastic discount factor:

$$
\begin{aligned}
S_{N t}^{w} & =\psi_{t} X_{t} H_{t}^{\alpha}-W_{t} H_{t}+E_{t}\left[M_{t, t+1}\left[S_{N t+1}^{w} \frac{\partial N_{t+1}}{\partial N_{t}}\right]\right] \\
S_{N t}^{w} & =\psi_{t} X_{t} H_{t}^{\alpha}-W_{t} H_{t}+(1-s) \beta E_{t}\left[\frac{\lambda_{t+1}^{C}}{\lambda_{t}^{C}} S_{N t+1}^{w}\right]
\end{aligned}
$$

The household's problem (4) is described by:

$$
\begin{aligned}
J_{t}= & \mathcal{U}\left(C_{t}, H_{t}, N_{t}\right)+\nu_{u} U_{t}+\beta E_{t}\left[J_{t+1}\right] \\
& +\lambda_{t}^{C}\left[\frac{B_{t-1}}{P_{t}}+W_{t} H_{t} N_{t}+b U_{t}+D_{t}-C_{t}-T_{t}-\frac{B_{t}}{P_{t} R_{t}}\right]
\end{aligned}
$$

and the laws of motion for employment, unemployment. We consider the case for household preferences over consumption and hours worked:

$$
\mathcal{U}\left(C_{t}, H_{t}, N_{t}\right)=\exp \left(\gamma_{t}\right) \frac{C_{t}^{1-\sigma}}{1-\sigma}+\nu_{0} \frac{\left(1-H_{t}\right)^{1-\nu_{1}}}{1-\nu_{1}} N_{t}
$$

Differentiating the household's value function, we obtain the marginal values of an employed and unemployed worker to the representative household:

$$
\begin{aligned}
J_{N, t} & =\frac{\partial \mathcal{U}(\cdot)}{\partial N_{t}}+\lambda_{t}^{C} W_{t} H_{t}+\beta E_{t}\left[(1-s) J_{N, t+1}+s J_{U, t+1}\right] \\
J_{U, t} & =\frac{\partial \mathcal{U}(\cdot)}{\partial U_{t}}+\lambda_{t}^{C} b+\beta E_{t}\left[f_{t} J_{N, t+1}+\left(1-f_{t}\right) J_{U, t+1}\right]
\end{aligned}
$$


The marginal benefit being employed over unemployment is:

$$
J_{N, t}-J_{U, t}=\lambda_{t}^{C} W_{t} H_{t}-\left(\lambda_{t}^{C} b+\frac{\partial \mathcal{U}(\cdot)}{\partial U_{t}}-\frac{\partial \mathcal{U}(\cdot)}{\partial N_{t}}\right)+\left(1-f_{t}-s\right) \beta E_{t}\left[J_{N, t+1}-J_{U, t+1}\right]
$$

for a match surplus to the household:

$$
\frac{J_{N, t}-J_{U, t}}{\lambda_{t}^{C}}=W_{t} H_{t}-Z_{t}+\left(1-f_{t}-s\right) \beta \frac{\lambda_{t+1}^{C}}{\lambda_{t}^{C}} E_{t}\left[\frac{J_{N, t+1}-J_{U, t+1}}{\lambda_{t+1}^{C}}\right]
$$

where

$$
Z_{t}=b+\frac{1}{\lambda_{t}^{C}}\left(\frac{\partial \mathcal{U}(\cdot)}{\partial U_{t}}-\frac{\partial \mathcal{U}(\cdot)}{\partial N_{t}}\right)=b+\frac{1}{\lambda_{t}^{C}}\left(\nu_{u}-\nu_{0} \frac{\left(1-H_{t}\right)^{1-\nu_{1}}}{1-\nu_{1}}\right)
$$

\section{B.1.2 Wages and hours}

Firms and workers engage in pairwise bargaining over wages and hours each period. Equilibrium wages and hours solve the problem

$$
\Lambda_{t}=\max _{W_{t}, H_{t}}\left(\frac{J_{N t}-J_{U t}}{\lambda_{t}^{C}}\right)^{\eta}\left(S_{N, t}^{w}-S_{V, t}^{w}\right)^{1-\eta}
$$

After first taking the log of the problem the first order condition for the wage is:

$$
\begin{aligned}
\frac{\partial \Lambda_{t}}{\partial W_{t}} & =\eta \frac{\lambda_{t}^{C}}{J_{N, t}-J_{U, t}} \frac{\partial\left(J_{N, t}-J_{U, t}\right)}{\partial W_{t}}+(1-\eta) \frac{1}{S_{N, t}^{w}} \frac{\partial S_{N, t}^{w}}{\partial W_{t}}=0 \\
\frac{\partial \Lambda_{t}}{\partial W_{t}} & =\eta \frac{\lambda_{t}^{C}}{J_{N, t}-J_{U, t}} H_{t}-(1-\eta) \frac{1}{S_{N, t}^{w}} H_{t}=0 \\
& \Rightarrow(1-\eta) \frac{J_{N, t}-J_{U, t}}{\lambda_{t}^{C}}=\eta S_{N, t}^{w}
\end{aligned}
$$

while the first order condition for hours is :

$$
\begin{aligned}
\frac{\partial \Lambda_{t}}{\partial H_{t}} & =\eta \frac{\lambda_{t}^{C}}{J_{N, t}-J_{U, t}} \frac{\partial\left(J_{N, t}-J_{U, t}\right)}{\partial H_{t}}+(1-\eta) \frac{1}{S_{N, t}^{w}} \frac{\partial S_{N, t}^{w}}{\partial H_{t}}=0 \\
& =\eta \frac{\lambda_{t}^{C}}{J_{N, t}-J_{U, t}}\left(W_{t}-\frac{\partial Z_{t}}{\partial H_{t}}\right)+(1-\eta) \frac{1}{S_{N, t}^{w}}\left(\alpha \psi_{t} X_{t} H_{t}^{\alpha-1}-W_{t}\right)=0 \\
& =\eta \frac{\lambda_{t}^{C}}{J_{N, t}-J_{U, t}}\left(-\frac{\partial Z_{t}}{\partial H_{t}}\right)+(1-\eta) \frac{1}{S_{N, t}^{w}}\left(\alpha \psi_{t} X_{t} H_{t}^{\alpha-1}\right)=0 \\
& =\left(-\frac{\partial Z_{t}}{\partial H_{t}}\right)+\left(\alpha \psi_{t} X_{t} H_{t}^{\alpha-1}\right)=0
\end{aligned}
$$


which results in, depending on the assumption made for $\mathcal{U}()$ on either:

$$
\begin{aligned}
\frac{\nu_{0}}{\lambda_{t}^{C}}\left(1-H_{t}\right)^{-\nu_{1}} & =\alpha \psi_{t} X_{t} H_{t}^{\alpha-1} \\
\nu_{0}\left(1-H_{t}\right)^{-\nu_{1}} & =\alpha \psi_{t} X_{t} H_{t}^{\alpha-1}
\end{aligned}
$$

To derive the wage:

$$
\begin{aligned}
& (1-\eta) \frac{J_{N, t}-J_{U, t}}{\lambda_{t}^{C}}=\eta S_{N, t}^{w} \\
& (1-\eta)\left[W_{t} H_{t}-Z_{t}+\left(1-f_{t}-s\right) \beta \frac{\lambda_{t+1}^{C}}{\lambda_{t}^{C}} E_{t}\left[\frac{J_{N, t+1}-J_{U, t+1}}{\lambda_{t+1}^{C}}\right]\right]=\eta\left[\psi_{t} X_{t} H_{t}^{\alpha}-W_{t} H_{t}\right. \\
& \left.+(1-s) \beta E_{t} \frac{\lambda_{t+1}^{C}}{\lambda_{t}^{C}} S_{N t+1}^{w}\right] \\
& (1-\eta)\left[W_{t} H_{t}-Z_{t}+\left(1-f_{t}-s\right) \beta \frac{\lambda_{t+1}^{C}}{\lambda_{t}^{C}} E_{t}\left[\frac{J_{N, t+1}-J_{U, t+1}}{\lambda_{t+1}^{C}}\right]\right]=\eta\left[\psi_{t} X_{t} H_{t}^{\alpha}-W_{t} H_{t}\right. \\
& \left.+(1-s) \beta E_{t} \frac{\lambda_{t+1}^{C}}{\lambda_{t}^{C}} S_{N t+1}^{w}\right] \\
& (1-\eta)\left[W_{t} H_{t}-Z_{t}-f_{t} \beta \frac{\lambda_{t+1}^{C}}{\lambda_{t}^{C}} E_{t}\left[\frac{J_{N, t+1}-J_{U, t+1}}{\lambda_{t+1}^{C}}\right]\right]=\eta\left[\psi_{t} X_{t} H_{t}^{\alpha}-W_{t} H_{t}\right] \\
& W_{t} H_{t}=\eta \alpha \psi_{t} X_{t} N_{t}^{\alpha-1} H_{t}^{\alpha}+(1-\eta) Z_{t}+(1-\eta) f_{t} \beta \frac{\lambda_{t+1}^{C}}{\lambda_{t}^{C}} E_{t}\left[\frac{J_{N, t+1}-J_{U, t+1}}{\lambda_{t+1}^{C}}\right] \\
& W_{t} H_{t}=\eta \psi_{t} X_{t} H_{t}^{\alpha}+(1-\eta) Z_{t}+\eta f_{t} \beta \frac{\lambda_{t+1}^{C}}{\lambda_{t}^{C}} E_{t}\left[S_{N, t+1}^{w}\right] \\
& W_{t} H_{t}=\eta \psi_{t} X_{t} H_{t}^{\alpha}+(1-\eta) Z_{t}+\eta f_{t}\left(\frac{\kappa_{t}}{q\left(\theta_{t}\right)-\lambda_{t}}\right) \\
& W_{t} H_{t}=\eta\left[\psi_{t} X_{t} H_{t}^{\alpha}+\kappa_{t} \theta_{t}\right]+(1-\eta) Z_{t}
\end{aligned}
$$

\section{B.2 Notes on the monetary policy rule}

Consider the deviations monetary policy rule for the gross nominal rate in the absence of a zero lower bound:

$$
R_{t}=R^{r} \Pi\left(\frac{\Pi_{t}}{\Pi^{*}}\right)^{\widehat{\phi}_{\pi}}\left(\frac{U_{t}}{U^{*}}\right)^{\widehat{\phi}_{u}}
$$

where $R^{r}$ is the real gross rate. The coefficient $\widehat{\phi}_{\pi}$ and $\widehat{\phi}_{u}$ correspond to the elasticities of $R_{t}$ to inflation $\Pi_{t}$ and $U_{t}$, respectively $\left(\left(\partial R_{t} / \partial \Pi_{t}\right)\left(\Pi_{t} / R_{t}\right)=\widehat{\phi}_{\pi}\right)$. 
Take the $\log$ of (A.8):

$$
\log \left(R_{t}\right)=\log \left(R^{r}\right)+\log (\Pi)+\widehat{\phi}_{\pi} \log \left(\frac{\Pi_{t}}{\Pi^{*}}\right)+\widehat{\phi}_{u} \log \left(\frac{U_{t}}{U^{*}}\right)
$$

Using the approximation for $|x|<1, \log (1+x) \approx x$, we have $\log \left(\frac{\Pi_{t}}{\Pi^{*}}\right) \approx \frac{\Pi_{t}-\Pi^{*}}{\Pi^{*}}$ and $\log \left(\frac{U_{t}}{U^{*}}\right) \approx$ $\frac{U_{t}-U^{*}}{U^{*}}$, such that the previous expression may be approximately rewritten as :

$$
R_{t}=r^{r}+\pi+\frac{\widehat{\phi}_{\pi}}{\Pi^{*}}\left(\pi_{t}-\pi^{*}\right)+\frac{\widehat{\phi}_{u}}{U^{*}}\left(U_{t}-U^{*}\right)
$$

The empirical literature estimates Taylor-type rules for the central bank policy setting very often use a specification of the type described by (A.10) to obtain values of $\phi_{\pi}=\frac{\widehat{\phi}_{\pi}}{\pi^{*}}$ and $\phi_{u}=\frac{\widehat{\phi}_{u}}{U^{*}}$.

\section{Summary of the Baseline Model}

\section{C.1 System of Model Equations}

The model's 17 endogenous variables, $N_{t}, U_{t}, H_{t}, V_{t}, \theta_{t}, q, f, W_{t}, M_{t}, \lambda_{t}^{C}, Z_{t}, Y_{t}, C_{t}, \psi_{t}$, $\Pi_{t}, \kappa_{t}, R_{t}$, are determined by the 17 equations that follow (ignoring the conditions for the Lagrange multiplier on the non-negativity constraint $\lambda_{t}^{V}$ ):

$$
\begin{aligned}
\psi_{t} & =\frac{\omega-1}{\omega}+\frac{\Omega}{\omega}\left[\frac{\Pi_{t}}{\Pi}\left(\frac{\Pi_{t}}{\Pi}-1\right)-E_{t} M_{t, t+1} \frac{Y_{t+1}}{Y_{t}} \frac{\Pi_{t+1}}{\Pi}\left(\frac{\Pi_{t+1}}{\Pi}-1\right)\right] \\
\frac{\kappa_{t}}{q\left(\theta_{t}\right)}-\lambda_{t}^{V} & =E_{t}\left[M_{t, t+1}\left[\psi_{t+1} X_{t+1} H_{t+1}^{\alpha}-W_{t+1} H_{t+1}+(1-s)\left[\frac{\kappa_{t+1}}{q\left(\theta_{t+1}\right)}-\lambda_{t+1}\right]\right]\right\} \\
W_{t} H_{t} & =\eta\left[\psi_{t} X_{t} H_{t}^{\alpha}+\kappa_{t} \theta_{t}\right]+(1-\eta) Z_{t} \\
Z_{t} & =b+\frac{1}{\lambda_{t}^{C}}\left(\nu_{u}-\nu_{0} \frac{\left(1-H_{t}\right)^{1-\nu_{1}}}{1-\nu_{1}}\right) \\
\frac{\nu_{0}}{\lambda_{t}^{C}}\left(1-H_{t}\right)^{-\nu_{1}} & =\alpha \psi_{t} X_{t} H_{t}^{\alpha-1} \\
\lambda_{t}^{C} & =\exp \left(\gamma_{t}\right) C_{t}^{-\sigma} \\
1 & =E_{t}\left[M_{t, t+1} \frac{R_{t}}{\Pi_{t+1}}\right] \\
M_{t, t+1} & =\beta\left(\frac{\lambda_{t+1}^{C}}{\lambda_{t}^{C}}\right) \\
Y_{t} & =C_{t}+\kappa_{t} V_{t}+\frac{\Omega}{2}\left(\frac{\Pi_{t}}{\Pi}-1\right)^{2} Y_{t} \\
Y_{t} & =X_{t} N_{t} H_{t}^{\alpha}
\end{aligned}
$$




$$
\begin{aligned}
\kappa_{t} & =\kappa_{0}+\kappa_{1} q_{t} \\
\theta_{t} & =\frac{V_{t}}{U_{t}} \\
N_{t+1} & =(1-s) N_{t}+q\left(\theta_{t}\right) V_{t} \\
U_{t} & =1-N_{t} \\
q_{t} & =\frac{1}{\left(1+\theta_{t}^{\iota}\right)^{1 / \iota}} \\
f_{t} & =\frac{1}{\left(1+\theta_{t}^{-\iota}\right)^{1 / \iota}}
\end{aligned}
$$

Deviations rule: $\quad R_{t}=\max \left[1, \quad R\left(\frac{\Pi_{t}}{\Pi^{*}}\right)^{\widehat{\phi}_{\pi}}\left(\frac{U_{t}}{U^{*}}\right)^{\widehat{\phi}_{u}}\right]$

Shortfalls rule: $\quad R_{t}=\max \left[1, \quad R\left(\frac{\Pi_{t}}{\Pi^{*}}\right)^{\widehat{\phi}_{\pi}}\left(\max \left[1, \frac{U_{t}}{U^{*}}\right]\right)^{\widehat{\phi}_{u}}\right]$ 